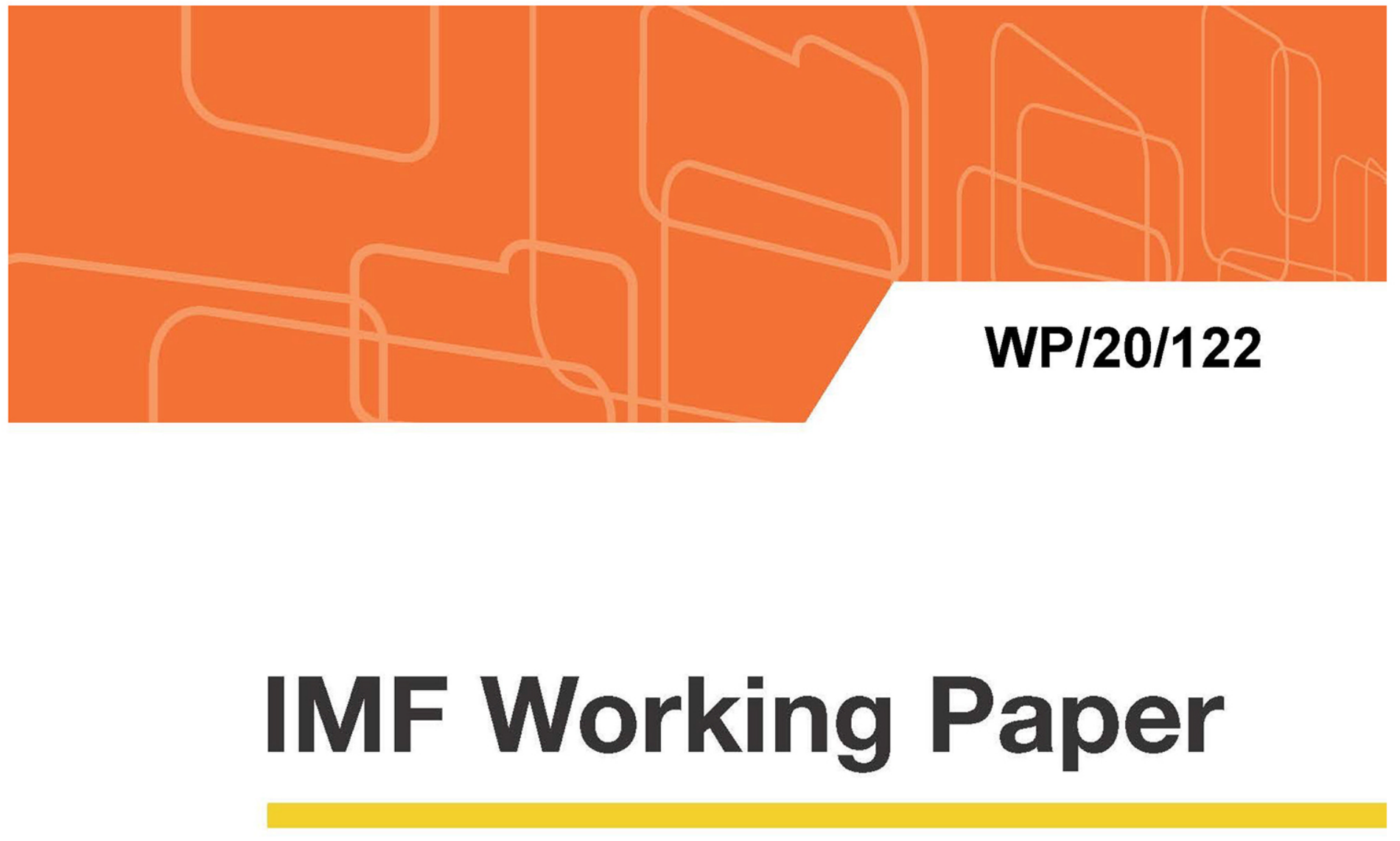

\title{
A Quantitative Model for the Integrated Policy Framework
}

by Tobias Adrian, Christopher Erceg, Jesper Lindé, Pawel Zabczyk, and Jianping Zhou

IMF Working Papers describe research in progress by the author(s) and are published to elicit comments and to encourage debate. The views expressed in IMF Working Papers are those of the author(s) and do not necessarily represent the views of the IMF, its Executive Board, or IMF management.

I N T E R N A T I O N A L M O N E T A R Y F U N D 


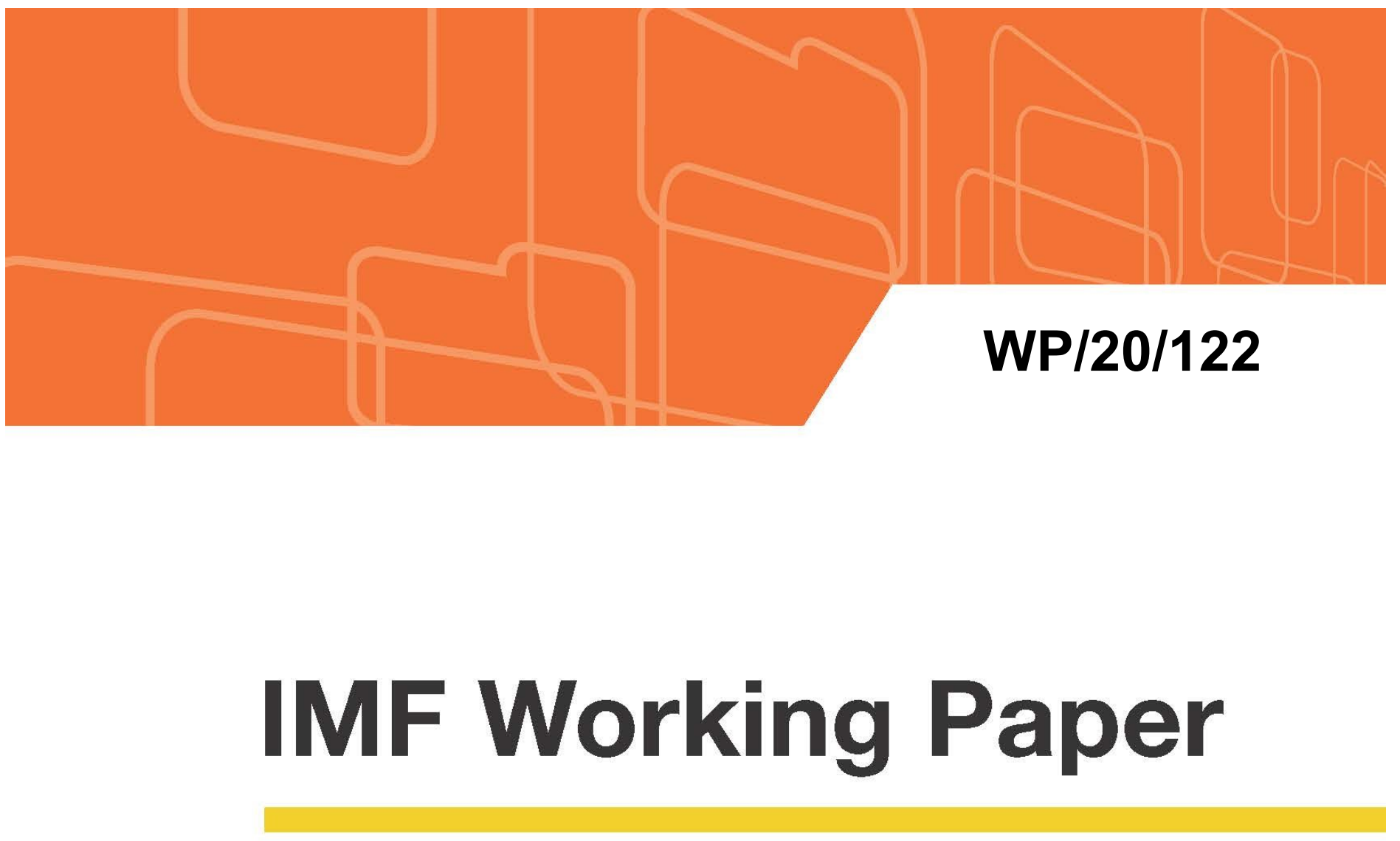

\section{A Quantitative Model for the Integrated Policy Framework}

by Tobias Adrian, Christopher Erceg, Jesper Lindé, Pawel Zabczyk, and Jianping Zhou

IMF Working Papers describe research in progress by the author(s) and are published to elicit comments and to encourage debate. The views expressed in IMF Working Papers are those of the author(s) and do not necessarily represent the views of the IMF, its Executive Board, or IMF management.

$$
\text { I N T E R N A T I O N A L M O N E T A R Y F U N D }
$$




\title{
IMF Working Paper
}

Monetary and Capital Markets Department

\section{A Quantitative Model for the Integrated Policy Framework}

\section{Prepared by}

\section{Tobias Adrian, Christopher Erceg, Jesper Lindé, Pawel Zabczyk, and Jianping Zhou*}

Authorized for distribution by Tobias Adrian

July 2020

Disclaimer: This document was prepared before COVID-19 became a global pandemic and resulted in unprecedented economic strains. It, therefore, does not reflect the implications of these developments and related policy priorities. We direct you to the IMF Covid-19 page that includes staff recommendations with regard to the COVID-19 global outbreak.

IMF Working Papers describe research in progress by the author(s) and are published to elicit comments and to encourage debate. The views expressed in IMF Working Papers are those of the author(s) and do not necessarily represent the views of the IMF, its Executive Board, or IMF management.

\begin{abstract}
Many central banks have relied on a range of policy tools, including foreign exchange intervention (FXI) and capital flow management tools (CFMs), to mitigate the effects of volatile capital flows on their economies. We develop an empirically-oriented New Keynesian model to evaluate and quantify how using multiple policy tools can potentially improve monetary policy tradeoffs. Our model embeds nonlinear balance sheet channels and includes a range of empirically-relevant frictions. We show that FXI and CFMs may improve policy tradeoffs under certain conditions, especially for economies with less well-anchored inflation expectations, substantial foreign currency mismatch, and that are more vulnerable to shocks likely to induce capital outflows and exchange rate pressures.
\end{abstract}

JEL Classification Numbers: C54, E52, E58, F41

Keywords: Monetary Policy, FX Intervention, Emerging Economies, DSGE Model.

Authors' E-Mail Addresses: TAdrian@IMF.org, CErceg@IMF.org, JLinde@IMF.org, PZabczyk@IMF.org, JZhou1@IMF.org

\footnotetext{
* We thank Suman Basu, Tam Bayoumi, Andrew Berg, Emine Boz, Luis Brandao Marques, Roberto Chang, Gaston Gelos, Gita Gopinath, David Hofman, Olivier Jeanne, Sebnem Kalemli-Ozcan, Gunes Kamber, Roland Meeks, Jonathan Ostry, Catherine Pattillo, Ratna Sahay, Lars E.O. Svensson, Susan Yang and participants at IMF seminars for useful comments. Special thanks to Christine Luttmer and Jie Yu for very helpful research assistance.
} 


\section{Contents}

1 Introduction $\quad \underline{1}$

2 The Model $\quad \underline{4}$

2.1 Aggregate Demand . . . . . . . . . . . . . . . . . . . $\underline{6}$

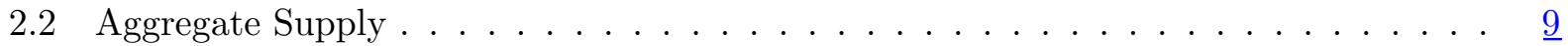

2.3 Monetary and Fiscal Policy . . . . . . . . . . . . . . . . . 13

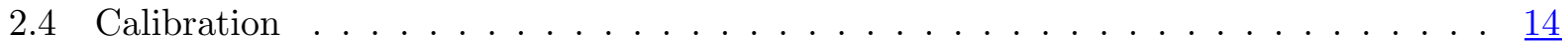

3 Shock Transmission in the Linear Model $\underline{16}$

3.1 UIP Risk Premium Shock Transmission: AEs vs EMEs . . . . . . . . . . . . . . . 17

3.2 Policy Tradeoffs in EMEs . . . . . . . . . . . . . . . . . 18

4 Shock Transmission in the Nonlinear Model $\quad \underline{20}$

4.1 Modeling of Endogenous Risk-Premiums . . . . . . . . . . . . . . . 21

4.2 Effects of FXI in a Crisis Situation . . . . . . . . . . . . . 25

4.3 Unconditional Distributions . . . . . . . . . . . . . . . . . 29

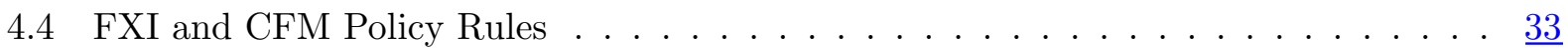

5 The Effects of FXI in a Liquidity Trap $\underline{37}$

6 Conclusion $\quad \underline{39}$

A The Model Environment $\underline{45}$

A.1 Households and Wage Setting . . . . . . . . . . . . . . . $\ldots$ 4

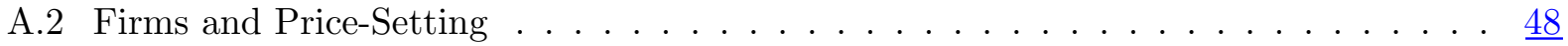

A.2.1 Final Goods Production . . . . . . . . . . . . . . . . $\underline{48}$

A.2.2 Production of Domestic Intermediate Goods . . . . . . . . . . . . . . . $\underline{49}$

A.2.3 Optimal Price Setting . . . . . . . . . . . . . . . . $\underline{50}$

A.3 Monetary and Fiscal Policy . . . . . . . . . . . . . . . 50

A.4 Importing and Exporting Firms . . . . . . . . . . . . . . . . $\underline{51}$

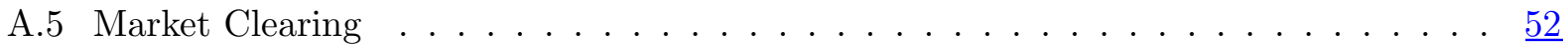




\section{Introduction}

Over the last two decades, many emerging market economies (EMEs) have moved away from fixed exchange rate regimes and adopted a monetary policy framework based on inflation targeting (IT). The IT framework, first introduced in New Zealand in 1990 and then in many other advanced economies (AEs), was found to be successful in stabilizing both inflation and real aggregates (Svensson, 2010). A rich literature followed, providing theoretical underpinnings for IT (Clarida et al., 1999). Experiences of emerging (and developing) countries also suggest that, on average, countries adopting inflation targeting outperformed comparators with other monetary policy frameworks(International Monetary Fund, 2006).

However, unlike their advanced economy counterparts, many EME central banks with IT frameworks have continued to rely on foreign exchange interventions (FXIs) in their monetary policy operations, and some also use capital flow management tools (CFMs). The use of these tools is particularly evident during episodes of volatile capital flows (Hoffmann et al., 2019). Indeed, volatile capital flows have frequently been a predominant concern for policy makers in EMEs, even if much less of a concern for policy makers in many AEs. EME policy makers often face policy dilemmas when hit by capital flow shocks (Ghosh et al., 2017). For example, lowering interest rates to deter capital inflows may lead to domestic credit booms and increase financial stability risks, while contractionary monetary policy during a capital outflow episode may further undermine economic activity and in so doing exacerbate the outflows.

Vegh and Vuletin (2013) provided empirical evidence that - for about half of the emerging market and developing countries in their sample - monetary policy responses to adverse capital flow shocks were procyclical, and outflow shocks were often met with tighter monetary policy. By contrast, in small open advanced economies domestic considerations dominate and adverse external shocks are usually met with monetary policy easing, which cushions the effects of external tightening

CInternational Monetary Fund. Not for Redistribution 
on domestic demand. It has been argued that this disparity in responses reflects that EME central banks often pursue exchange rate and financial stability goals in addition to inflation stabilization, and that multiple objectives require multiple instruments (Ghosh et al., 2016). To that effect, some emerging markets appear to "lean against" capital inflows by accumulating reserves when global financial conditions are easy and selling foreign currency when hit with outflow shocks. FXI and CFMs may mitigate the impact of capital inflows on domestic risk taking and hence help reduce the degree to which monetary policy has to tighten when capital flows out (Kalemli-Ozcan, 2019; Basu et al., 2020).

Our paper is motivated by the substantial empirical evidence showing that exchange rate changes tend to have larger and more persistent effects in emerging market economies than in advanced economies. ${ }^{1}$ We develop an empirically-oriented New Keynesian model - similar to those widely used by central banks - to help quantify how using multiple tools, including FXI and CFMs, can improve policy trade-offs. Our model includes a balance sheet channel capturing how exchange rate changes may have large effects on domestic financial conditions (in the spirit of Bruno and Shin, 2018). Moreover, the effects of shocks depend critically on the degree to which inflation expectations are anchored, with pronounced differences between advanced and emerging market economies.

The key factors influencing policy tradeoffs in our model are well illustrated by considering a UIP risk premium shock that causes the exchange rate to depreciate. In an advanced economy with well-anchored inflation expectations, the shock plays out like an expansionary aggregate demand shock, boosting output through expenditure-switching channels and exerting only short-lived effects on inflation (which monetary policy can "look through"). By contrast, the shock poses difficult tradeoffs for emerging markets: with inflation expectations less well-anchored, inflation rises

\footnotetext{
${ }^{1}$ The higher sensitivity appears partly attributable to relatively less well-anchored inflation expectations in many EMEs (see e.g. Chapter 3 in the IMF World Economic Outlook, 2018).
} 
persistently, and the tighter policy required to keep inflation in check may depress output. The output contraction may be amplified to the extent the weaker exchange rate tightens domestic borrowing conditions.

We use our model to highlight key determinants of the tradeoffs facing EMEs, and to characterize how using FXI or capital flow management tools can improve on a simple reliance on conventional policy. Using simulations of a nonlinear variant of our model, we show how the benefits of these tools are more pronounced for economies with weak initial conditions (e.g., high debt) that are particularly susceptible to shifts in global investor sentiment. Stochastic simulations of our model help elucidate how these tools may be used systematically to reduce downside risks to GDP.

While our model highlights that FXIs and CFMs can improve policy tradeoffs under certain conditions, additional considerations - not fully addressed by our model - must be taken into account when deciding whether or not to utilize these tools in practice. Thus, our model results should not be taken as an unqualified endorsement of the use of these tools either in general or in specific situations. First, while our model (in effect) assumes perfect foresight, decisions about whether to use these tools must often be made under considerable uncertainty about the underlying shocks and the efficacy of policy actions. For instance, using FX sales to support the exchange rate may risk large and potentially destabilizing losses of reserves if the shock is more persistent than anticipated and requires the equilibrium real exchange rate to depreciate. Second, the use of FXI and CFMs may have substantial longer-term costs. Policies that stabilize the exchange rate may impede the development of hedging markets, and encourage an excessive buildup of foreign currency debt that may amplify vulnerabilities; and frequent resort to CFMs may deter foreign investment and slow financial market development. A full analysis of these potential benefits and costs is essential for determining appropriate policy, though we see our modeling framework as providing important input into making that assessment. 
Our work is related to the literature on FX intervention and monetary credibility. A number of recent papers analyze the use of FXIs as an additional policy instrument, focusing on the effects on the exchange rate (e.g. Adler et al., 2019; Blanchard et al., 2015; Daude et al., 2016; Fratzscher et al., 2019) and the macro-economy (Qureshi et al., 2011; Ghosh et al., 2015; Blanchard et al., 2017; Cavallino, 2019). FXIs are also justified when financial market imperfections distort efficient resource allocation, with levels of financial development distinguishing emerging markets from small open advanced economies (for example, deep FX markets in AEs but not in EMs are discussed in Mano and Sgherri, 2020) There are also vast literatures on the benefits of conducting FXI interventions, both for mercantilist and precautionary motives (Jeanne and Korinek, 2010; Jeanne, 2016), as well as on drawbacks due to fiscal costs (Adler and Mano, 2016) and a heightened incentive for FX leveraging by domestic corporations.(Tong and Wei, 2019).

The remainder of the paper is organized as follows. We start by providing an overview of our benchmark model and assumptions in Section 2. Deterministic and stochastic simulation results illustrating when FXIs could be helpful in achieving monetary policy objectives and lifting the country from a liquidity trap are presented in Sections 3, 4 and 5, respectively. Section 6 summarizes the policy implications and concludes.

\section{The Model}

Our New Keynesian small open economy model builds on workhorse models in the literature, including Galí and Monacelli (2005). We extend these models along several dimensions both to enhance empirical realism and to help capture key features of EME economies. First, our model incorporates a broader array of real and nominal rigidities, including habit persistence in consumption, sticky wages and prices, and imperfect passthrough of exchange rate changes to traded goods prices. While local currency pricing is our benchmark, our model also allows for producer 
currency pricing and dominant currency pricing (Gopinath et al., 2016). Second, we allow for the possibility that some agents form inflation expectations adaptively to capture imperfect credibility of monetary policy. This feature is important in accounting for how exchange rate changes may have large second round effects on inflation that often complicate monetary policy tradeoffs in EMEs. Third, our model assumes incomplete markets, so that domestic agents must borrow or invest in a foreign currency-denominated bond, in contrast to the assumption of full international risk sharing in Galí and Monacelli (2005). Fourth, we allow for discounting in key aggregate demand and supply equations in the spirit of Gabaix (2016). This feature mitigates the forward guidance puzzle, so that policies that operate by affecting long-horizon forward rates have less traction in stimulating aggregate demand and inflation today.

While our core model can be regarded as a log-linearized version of this DSGE framework, we introduce several key nonlinear features. First, we allow for a nonlinear UIP risk premium specifying that the return required by investors on domestic borrowing rises sharply when net foreign liabilities exceed a threshold level. Second, we assume that the spread facing domestic borrowers rises nonlinearly as the home currency depreciates. This feature, in the spirit of (Bruno and Shin, 2018), proxies for how depreciations may lead to a sharp tightening of domestic financial conditions if there is significant unhedged foreign currency debt. Lastly, we allow for the possibility that policy rates may be constrained by the effective lower bound.

We next provide an overview of the (largely) log-linearized model that we use in our subsequent analysis, and highlight the several key sources of nonlinearities. The Technical Appendix includes a full description of our modeling framework including first order conditions. 


\subsection{Aggregate Demand}

The home economy resource constraint is expressed as a share-weighted average of home consumption $c_{t}$, government spending $g_{t}$, and "net exports" (the difference between exports $m_{c, t}^{*}$ and imports $\left.m_{c, t}\right)$ weighted by the (steady-state) trade share $m_{y}$

$$
y_{t}=c_{y} c_{t}+g_{y} g_{t}+m_{y}\left(m_{c, t}^{*}-m_{c, t}\right)
$$

Imports expand as domestic consumption rises and fall in response to an increase in their relative price, so that import demand is given by

$$
m_{c, t}=c_{t}-\varepsilon_{c} \gamma_{t}^{m, c}
$$

where $\gamma_{t}^{m, c}=p_{m, t}-p_{c, t}$ is the price of a bundle of imported goods relative to that of a consumption basket comprising both domestically-produced and imported goods. This relative price reduces to the consumption-based real exchange rate $q_{c t}=p_{t}^{*}+s_{t}-p_{c, t}$ under the assumption of full pass-through $\left(p_{m, t}=p_{t}^{*}+s_{t}\right)$ from exchange rates to import prices.

Similarly, export demand $m_{c, t}^{*}$ rises with foreign consumption $c_{t}^{*}$ and falls with the relative price of exported goods (produced by home exporters) to that of their foreign competitors, $\gamma_{t}^{x, *}=p_{x, t}-p_{t}^{*}$,

$$
m_{c, t}^{*}=c_{t}^{*}-\varepsilon_{c}^{*} \gamma_{t}^{x, *}
$$

When foreign currency prices of home products move one-to-one with the exchange rate, we have $\gamma_{t}^{x, *}=p_{t}-s_{t}-p_{t}^{*}$, and the real exchange rate is given by $q_{p, t}=s_{t}+p_{t}^{*}-p_{t}$.

Consumption demand is determined by the consumption Euler equation linking the marginal utility of consumption $\lambda_{c, t}$ to future marginal utility of consumption and short-term real interest 
rates faced by consumers $r_{b, t}$,

$$
\lambda_{c, t}=\delta_{c} \lambda_{c, t+1}+r_{b, t} .
$$

The marginal utility of consumption varies inversely with current consumption, but rises with past consumption, with the latter reflecting habit persistence in consumption,

$$
\lambda_{c, t}=-\frac{1}{\widehat{\sigma}}\left(c_{t}-\varkappa_{c} c_{t-1}-\epsilon_{c, t}\right) .
$$

Taken together, these equations imply that consumption demand depends on a long-term real interest rate $r_{b, t}^{L}$, but with an important caveat that this borrowing rate depends on a discounted sum of future short rates:

$$
c_{t}-\varkappa_{c} c_{t-1}-\epsilon_{c, t}=\widehat{\sigma} E_{t} \sum_{j=0}^{\infty} \delta_{c}^{j} r_{b, t+j}=\widehat{\sigma} r_{b, t}^{L}
$$

The inclusion of discounting is in the spirit of the behavioralist New Keynesian model of Gabaix (2016) and it implies that future short term real interest rates have muted effects on current consumption demand. ${ }^{2}$

In addition to allowing for discounting, our model departs from the standard New Keynesian setup by assuming that the borrowing rate facing home consumers includes a time-varying "private borrowing spread" $\Psi_{t}$ :

$$
r_{b, t}^{L}=E_{t} \sum_{j=0}^{\infty}\left\{\delta_{c}^{j}\left(i_{t+j}-\pi_{c, t+j+1}\right)+\delta_{c}^{j}\left(i_{b, t+j}-i_{t+j}\right)\right\}=r_{t}^{L}+\Psi_{t}
$$

where $r_{t}^{L}$ is the long-term real interest rate on government bonds, and the interest rate spread $\Psi_{t}$ is a discounted sum of future gaps between the nominal borrowing rate and policy rate, i.e., ${ }^{2}$ Accordingly, forward guidance about future monetary policy actions would have much smaller effects in this setup than in the standard workhorse New Keynesian model. 
$\Psi_{t}=E_{t} \sum_{j=0}^{\infty} \delta_{c}^{j}\left(i_{b, t+j}-i_{t+j}\right)$

The private borrowing spread is assumed to rise when the real exchange rate depreciates

$$
\Psi_{t}=f\left(q_{c, t}\right)
$$

capturing a balance sheet channel of transmission, whereby an exchange rate depreciation may cause debt and debt-servicing costs to jump and financial conditions to tighten, particularly when a substantial part of borrowing represents unhedged foreign currency debt. More specifically, the function $f\left(q_{c, t}\right)$ is upward sloping and locally convex, which allows for the possibility that depreciations above a certain threshold may exert large nonlinear effects on financial conditions even while small depreciations may have only minimal effects.

We assume that uncovered interest parity (UIP) does not hold in the short run. The aggregate demand block of the model thus includes a risk-augmented UIP equation and an equation for the evolution of the home economy's net foreign liabilities. The UIP equation is specified as

$$
q_{c, t}=\delta_{c} q_{c, t+1}+\left(i_{t}^{*}-\pi_{c, t+1}^{*}\right)-\left(i_{t}-\pi_{c, t+1}\right)+\Phi\left(d_{t}, \bar{d}_{t}, b_{t}\right)-\tau_{t},
$$

and implies that the real exchange rate depreciates (i.e., $q_{c, t}$ rises) when the foreign real interest rate rises relative to the domestic interest rate, or if the UIP risk premium $\Phi(\cdot)$ rises; conversely, it appreciates in response to a tax on capital outflows $\tau_{t}$. The time-varying UIP risk premium $\Phi(\cdot)$ implies that investors require significantly higher expected returns if the home economy's net foreign liabilities $d_{t}$ rise relative to a threshold level of $\bar{d}_{t}$ and in times of market stress. The government may reduce this UIP risk premium directly by using foreign exchange intervention. Foreign exchange sales $\left(-b_{t}\right)$ strengthen the demand for home currency and thus may reduce the foreign exchange risk-premium under conditions detailed in Section 4.1. 
The aggregate demand block of the model is completed with the equation describing the evolution of net foreign liabilities. As the home economy is assumed to be restricted to borrowing (or lending) abroad in the foreign currency, its net foreign liabilities (as a share of GDP) evolve according to:

$$
d_{t}=\left(1+r_{d, t}\right) d_{t-1}-m_{y}\left(m_{c, t}^{*}+\gamma_{t}^{x, *}-m_{c, t}\right) .
$$

In a standard linearized setup with a zero steady-state debt, the term $\left(1+r_{d, t}\right)$ simply equals to the steady-state gross real interest rate $\left(1+r_{d}\right)$. Accordingly, small variations in other variables, including the exchange rate, do not trigger any endogenous feedback on debt service costs. However, in the nonlinear specification of the model considered in Section 4 , the real interest rate $r_{d, t}$ is determined by

$$
\left.\left(1+r_{d, t}\right)=\frac{1+i_{t-1}^{*}}{1+\pi_{d, t}} \frac{S_{t}}{S_{t-1}}\left[1+\Phi\left(d_{t-1}, \bar{d}_{t-1}, b_{t-1}\right)\right)\right]
$$

This expression highlights how the domestic real interest rate is influenced by the foreign interest rate, domestic inflation, the change in the nominal exchange rate, as well as the previous period riskpremium $\Phi\left(d_{t-1}, \bar{d}_{t-1}, b_{t-1}\right)$. Ceteris paribus, a higher foreign nominal interest rate increases debt service costs, as does a depreciation of the domestic currency; whereas higher domestic inflation lowers it.

\section{$2.2 \quad$ Aggregate Supply}

Turning to the supply side, the price-setting equation takes the form of a modified New Keynesian Phillips Curve:

$$
\pi_{t}-\iota_{d} \pi_{t-1}=\beta \delta_{\pi}\left(\pi_{t+1}-\iota_{d} \pi_{t}\right)+\kappa_{m c} m c_{t}
$$

This specification is based on Calvo-style price setting, with the sensitivity of inflation $\pi_{t}$ (on do-

mestically produced goods) to marginal cost $m c_{t}$ determined by the slope coefficient $\kappa_{m c}$, which 
itself varies inversely with the mean duration of price contracts. The Phillips Curve is assumed to embed some structural persistence that is determined by the indexation parameter $\iota_{d}$. This persistence may be interpreted as reflecting dynamic indexation (as in Christiano et al., 2005) or inflation expectations with an adaptive component (as in Clarida et al., 1999). Our preferred interpretation is along the latter lines, as it highlights the role of imperfect central bank credibility and the ability of the central bank to anchor inflation expectations. Either interpretation is consistent with cost shocks exerting highly persistent "second round" effects on inflation. In addition, and as in the "IS Curve" (eq. 4) discussed above, we allow for discounting $\delta_{\pi}$ that damps the influence of future marginal cost on current inflation. We also retain the assumption of full indexation of prices in the non-stochastic formulation of our model, which implies that the steady-state embeds no price distortions.

Marginal cost $m c_{t}$ rises with an increase in the producer real wage $\xi_{t}$, and falls with a decline in the marginal product of labor $m p l_{t}$

$$
m c_{t}=\xi_{t}-m p l_{t}=\xi_{t}-\left(y_{t}-l_{t}\right)
$$

The marginal product of labor is based on a Cobb-Douglas production function:

$$
y_{t}=(1-\alpha)\left(l_{t}+z_{t}\right) \text {. }
$$

Turning to labor supply, the marginal rate of substitution $m r s_{t}$ between consumption and leisure - which determines the cost of working an additional hour in terms of consumption goods - is given by

$$
m r s_{t}=\chi l_{t}-\lambda_{c, t},
$$


and hence rises as hours worked increase or as the marginal utility of consumption declines. To highlight how exchange rate depreciation can put upward pressure on (product) wages and hence firm marginal costs, it's helpful to consider the special case in which wages are fully flexible and there is full passthrough of exchange rate changes to consumer prices (i.e, producer currency pricing). In this case, the product real wage facing firms can then be expressed as

$$
\xi_{t}=\omega\left(p_{m, t}-p_{t}\right)+\xi_{c, t}=\frac{\omega}{1-\omega} q_{c, t}+m r s_{t}
$$

Thus, exchange rate depreciation boosts the relative price of imported goods, causing households to demand a higher real wage in terms of the home produced good $\xi_{t}$ to keep their purchasing power intact (as required to induce them to work the same number of hours and leave their $m r s_{t}$ unchanged). The extent of upward pressure on firms' costs rises with the openness of the economy, but is damped if passthrough from exchange rates to import prices is muted (as in our benchmark calibration which assumes local currency pricing).

In our baseline specification, nominal wages are sticky and set in Calvo-style wage contracts and the wage Phillips curve takes the following form

$$
\omega_{t}-\iota_{w} \pi_{c, t}^{L}=\beta \delta_{\pi}\left(\omega_{t+1}-\iota_{w} \pi_{c, t+1}^{L}\right)+\kappa_{w}\left(m r s_{t}-\xi_{c, t}\right),
$$

hence, nominal wage inflation $\omega_{t}$ depends on future wage inflation and the gap between the marginal cost of work and the consumption real wage. This setup allows for a flexible specification of wage indexation in which the relevant inflation measure indexing wages is a long moving average of either past realized inflation, or of exchange rate changes:

$$
\pi_{c, t}^{L}=(1-\Phi) \pi_{c, t}^{L}+\Phi\left(\xi \pi_{c, t-1}+(1-\xi) \Delta q_{c, t-1}\right)
$$


The dependence of wage inflation on past exchange rate changes allows for substantial second round effects through a wage channel. The product real wage is determined by the identity:

$$
\xi_{t}=\xi_{t-1}+\omega_{t}-\pi_{t}
$$

with the consumption real wage given by equation (16).

Our model allows for deviations from the law of one price in both the import and export sector. Thus, there are Phillips curves that are relevant for determining import prices and export prices, with both derived from Calvo-style pricing assumptions. Specifically, the price-setting for both consumer-goods imports $(m)$ and domestic exports $(x)$ sectors are given by

$$
\xi_{j} \pi_{j, t}=\frac{\xi_{j} \beta}{1+\iota_{j} \beta} \pi_{j, t+1 \mid t}+\frac{\xi_{j} \iota_{j}}{1+\iota_{j} \beta} \pi_{j, t-1}+\frac{\left(1-\xi_{j}\right)\left(1-\beta \xi_{j}\right)}{1+\iota_{j} \beta}\left(m c_{j, t}+\varrho_{j, t}\right),
$$

where $\pi_{j, t}, j \in\{m, x\}$, denotes the deviation in quarter $t$ of the log of gross inflation from its steady state $\left(\pi_{j, t} \equiv d \Pi_{j, t} / \Pi_{j}\right.$, where $\Pi_{j, t} \equiv P_{j, t} / P_{j, t-1}$ is gross inflation, $P_{j, t}$ is the price level, and $\Pi_{j}$ is the steady-state gross inflation rate in sector $\left.j\right) ; \iota_{j}$ and $\xi_{j}$ are parameters $\left(\xi_{j}\right.$ is the Calvo price-stickiness parameter); $m c_{t}$ denotes the real marginal cost of firms in sector $j$; and $\varrho_{j, t}$ denotes a time-varying markup in sector $j$, assumed to be i.i.d. and $N\left(0, \sigma_{\varrho_{j}}^{2}\right)$. Firms in sector $j$ that do not optimize their price in a given quarter are assumed to index them to the previous quarter's inflation in the sector and the steady state inflation target according to $\iota_{j} \Pi_{j, t-1}+\left(1-\iota_{j}\right) \Pi_{j}$ so the parameter $\iota_{j}$ is an indexation parameter reflecting the weight on dynamic (lagged) inflation component. Firms' marginal costs are further defined as

$$
\begin{aligned}
m c_{x, t} & =p_{t}-s_{t}-p_{x, t} \equiv m c_{x, t}+\pi_{t}-\pi_{x, t}-\Delta s_{t} \\
m c_{m, t} & =p_{t}^{*}+s_{t}-p_{m, t} \equiv-m c_{x, t}-\gamma_{t}^{x, *}-\gamma_{t}^{m, d}
\end{aligned}
$$


where the two relative prices $\gamma_{t}^{x, *}$ and $\gamma_{t}^{m, d}$ are given by

$$
\begin{aligned}
\gamma_{t}^{x, *} & \equiv p_{x, t}-p_{t}^{*} \equiv \gamma_{t-1}^{x, *}+\pi_{x, t}-\pi_{t}^{*} \\
\gamma_{t}^{m, d} & \equiv p_{m, t}-p_{t} \equiv \gamma_{t-1}^{m, d}+\pi_{m, t}-\pi_{t}
\end{aligned}
$$

Finally, consumer price inflation is defined as

$$
\pi_{c, t}=\left(1-m_{c}\right) \pi_{t}+m_{c} \pi_{m, t}
$$

where $m_{c}=m_{y}\left(1-g_{y}\right)$, i.e. we assume that there is only trade in private consumption goods, and $\pi_{m, t}$ denotes the local currency price of imported goods. In the special case of full pass-through, equation (25) simplifies to $\pi_{c, t}=\pi_{t}+m_{c} \Delta q_{c, t}$. Notably, our modeling of imperfect pass-through of exchange rate movements to export and import prices nests both local, producer and dominant currency pricing as special cases.

\subsection{Monetary and Fiscal Policy}

The central bank is assumed to follow a Taylor-style policy rule

$$
i_{t}=\max \left\{-i,\left(1-\gamma_{i}\right)\left[\gamma_{\pi}\left(\bar{\pi}_{c, t+4 \mid t}+\bar{\pi}_{c, t}\right)+\gamma_{y} y_{t}\right]+\gamma_{i} i_{t-1}+e_{i, t}\right\}
$$

where $i$ is the steady-state nominal interest rate (since variables are measures relative to steady state levels, $i_{t}=-i$ implies that the policy rate reaches its assumed lower bound of zero). The rule specifies that the central bank considers both the expected and current four quarter change in the core CPI inflation rate, noting that $\bar{\pi}_{c, t}=\left(\bar{\pi}_{c, t}+\bar{\pi}_{c, t-1}+\bar{\pi}_{c, t-2}+\bar{\pi}_{c, t-3}\right) / 4$. It also takes domestic output (measured as deviation from its trend path) into account. Our assumption that the central 
bank responds to core CPI inflation in essence means that the central bank puts some weight on responding to import price inflation $\pi_{m, t}$. The parameter $\gamma_{i}$ allows for interest rate smoothing and $e_{i, t}$ is an interest rate shock.

Government expenditure $g_{t}$ in eq. (1) is assumed to follow an exogenous AR(1) process (see below for more details). The steady-state level of $g$ is financed by labor income taxes, but any variations in government spending around its steady state are assumed to be paid for via lump-sum taxes. This simplifying assumption allows us to abstract from the dynamic aspects of fiscal policy.

\subsection{Calibration}

We calibrate our model at a quarterly frequency using fairly standard parameter values. For tractability, the calibration is identical for advanced and emerging market economies with two key exceptions. First, we allow the parameters governing price and wage formation to differ, to capture less-well anchored inflation expectations in EMEs relative to AEs. Second, the EME formulation of the model allows for two key nonlinear balance sheet channels (via an endogenous UIP risk premium $\Phi\left(d_{t}, \overline{d_{t}}, b_{t}\right)$ in eq. (9) and an endogenous private borrowing spread $\Psi_{t}$ in eq. (7)).

The responsiveness of inflation to marginal cost and of wages to the labor market wedge plays a key role in determining how monetary policy actions affect output and inflation, as well as the extent to which medium-term inflation expectations respond to shocks. The calibration for the AE economy relies on findings in the literature on estimated DSGE models (see Lindé et al., 2016; Del Negro et al., 2013; Campbell et al., 2012), specifically the low slopes of the price and wage curves (i.e. $\kappa_{p}$ and $\kappa_{w}$ ) and that structural persistence in price and wage inflation is also low (i.e. $\iota_{p}$ and $\iota_{w}$ are small). In line with the literature, we use $\kappa_{p}=.005$ and $\kappa_{w}=.02$ and $\iota_{p}=.5$ and $\iota_{w}=0$ as our "AE calibration." ${ }^{3}$ For the EMEs, we set the parameters capturing the degree of

\footnotetext{
${ }^{3}$ In the standard homogenous capital and labor Calvo model with a Dixit-Stiglitz aggregator, this is equivalent to assuming that the firm's (union's) probability of not being able to re-optimize prices (wages) equals 0.92 (0.87).
} 
structural persistence in inflation and wages $\left(\iota_{P}\right.$ and $\left.\iota_{w}\right)$ to 0.75 , to capture the greater degree to which inflation expectations depend on realized inflation and wages. The slope of the price and wage Phillips curves $\left(\kappa_{p}\right.$ and $\left.\kappa_{w}\right)$ are also set notably higher than in the AE case (.02 and .03, respectively). ${ }^{4}$

The other parameters are the same for both AE and EME economies. The term $\pi_{c, t}^{L}$ capturing the "trend inflation" rate to which wages are indexed assumes that $\Phi=.05$ and $\xi=1$, which implies that this trend inflation measure is a long distributed lag of past inflation. This parametrization is identical for both AEs and EMEs. A discount factor of $\beta=0.995$ implies a steady-state real interest rate of 2 percent (at an annualized rate). With an annualized steady-state inflation rate of 2 percent (i.e., $\pi=0.005$ ), the steady-state annualized nominal interest rate equals 4 percent (so $i=0.01$ ). We set the intertemporal substitution elasticity $\sigma$ to 1 , which is consistent with $\log$ utility. ${ }^{5}$ The habit parameter $\varkappa_{c}$ is set to 0.8 . The Frisch elasticity of labor supply of $\frac{1}{\chi}=0.5$ and capital share of $\alpha=0.3$ are in the typical range specified in the literature. The government share of steady state output is set to 20 percent $\left(g_{y}=0.2\right)$. In the spirit of Gabaix (2016), we allow for discounting in the consumption euler, UIP, and price-setting equations by setting $\delta_{c}=0.95$, and $\delta_{\pi}=0.92$.

In the baseline calibration of the parameters in the monetary policy rule $(26)$, we set $\gamma_{\pi}=$ $1.5, \gamma_{y}=.0625$, and $\gamma_{i}=0$. The coefficient on the output gap, which is 0.25 at an annual rate, is modestly lower than in the standard Taylor rule (0.50).

Turning to trade, we assume that import and export prices are consistent with "local currency pricing" so that both are sticky in the local currency. Our calibration implies that import and export prices are more responsive to marginal costs in EMEs relative to AEs, and structural per-

\footnotetext{
${ }^{4}$ In the standard homogenous capital and labor Calvo model with Dixit-Stiglitz aggregator, this is equivalent to assuming that firms and unions re-optimize their prices and wages on average once per year.

${ }^{5}$ The scale parameter on the consumption taste shock $\nu$ is set to 0.001 in order to have a negligible impact on the slope of the IS curve.
} 
sistence also noticeably higher. ${ }^{6}$ The parameter $\varepsilon_{c}$ determining the sensitivity of imports to the real exchange rate is set to 0.8 , as is its export counterpart $\varepsilon_{c}^{*}$. These values are consistent with evidence about trade price elasticities for a large set of both advanced and emerging market economies. We further assume a 20 percent import share, i.e. we set $m_{y}$ equal to $0.2 .^{7}$

The exogenous shocks $s_{t}=\left\{g_{t}, \epsilon_{c, t}, e_{i, t}, c_{t}^{*}, r_{t}^{*}, \overline{d_{t}}, b_{t}, \tau_{i, t}, \tau_{o, t}\right\}$ are assumed to follow AR(1) processes

$$
s_{t}=\rho_{s} s_{t-1}+e_{s, t}, e_{s, t} \sim i . i . d .\left(0, \sigma_{s}^{2}\right)
$$

where the persistence $\rho_{s}$ and standard deviation of each shock $\left(\sigma_{s}\right)$ process will be described when they are used in the analysis.

Finally, we solve the model using Dynare, documented in Adjemian et al. (2011).

\section{Shock Transmission in the Linear Model}

We begin by showing that the transmission of a UIP risk premium shock can vary substantially depending on key structural features of the economy, including the degree to which inflation expectations are well-anchored. These are captured by different calibrations of slopes of the price and wage curves and degrees of indexation $\left(\kappa_{p}, \kappa_{w}, \iota_{P}\right.$ and $\left.\iota_{w}\right)$, as noted earlier in the calibration section. We also demonstrate that these structural features have important implications for the tradeoffs faced by policymakers. For concreteness, we compare an economy with well-anchored inflation expectations - which we call an "advanced economy" - with one in which inflation expectations are less well-anchored - subsequently referred to as "emerging market economy."

\footnotetext{
${ }^{6}$ To be specific, import and export firms in EMEs (AEs) adjust their prices on average every 3 (5) quarters (that is $\xi_{x}=\xi_{m}=.667$ in EMEs and $0.8 \mathrm{in} \mathrm{AEs),} \mathrm{and} \mathrm{the} \mathrm{indexation} \mathrm{coefficients} \iota_{x}$ and $\iota_{m}$ are 0.75 in EMEs and 0.5 in AEs.

${ }^{7}$ This is lower than in many small open economies. However, our model does not allow imports to be used as inputs into export good production, which tends to magnify national accounts estimates of the import share.
} 


\subsection{UIP Risk Premium Shock Transmission: AEs vs EMEs}

Figure 1: Transmission of Risk-Premium Shocks in Advanced and Emerging Markets.
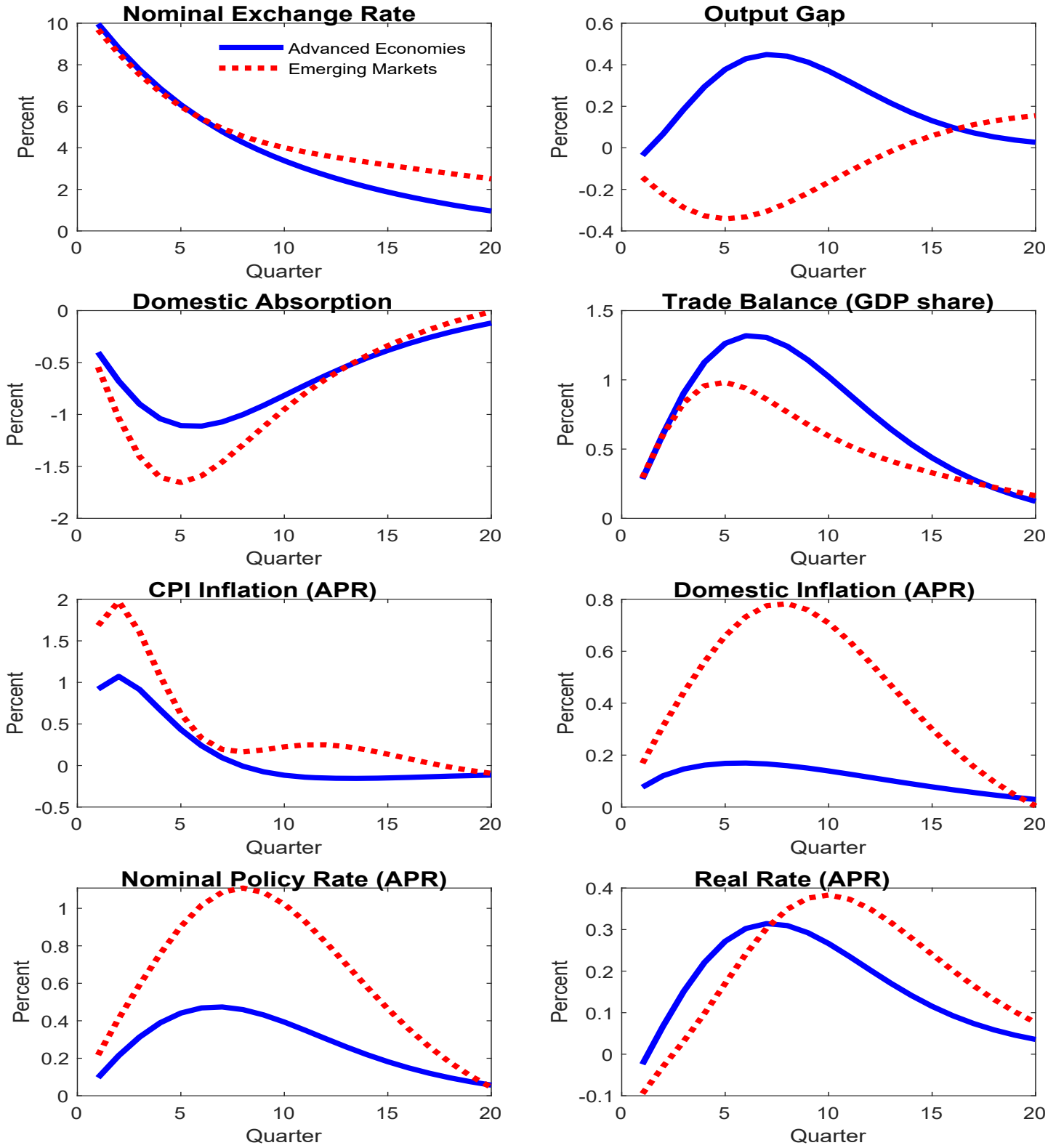

In this section, we assess the effects of an investor risk tolerance shock $\bar{d}_{t}$ that causes investors to be less willing to hold bonds issued by the home economy and is tantamount to a UIP risk premium shock. In particular, investors demand a higher expected return on the bonds issued by home agents relative to those issued by foreign residents (inclusive of expected currency appreciation). 
The shock is assumed to follow an $\operatorname{AR}(1)$ process with $\rho_{\bar{d}}=0.9$ and is scaled so that the real exchange rate depreciates by 10 percent in the AE economy (Figure 1).

For the AE, the shock does not pose a major policy challenge (blue lines). The exchange rate depreciation stimulates net exports, causing output to rise. The combination of higher output and higher import prices causes inflation to rise, but with well-anchored inflation expectations monetary policy can "look through" the transient rise in inflation and focus on output. All told, the shock looks very similar to a "standard" aggregate demand shock, notwithstanding the transient initial boost in inflation.

The same shock, by contrast, generates a more difficult policy tradeoff in the EME economy (red dotted line). While the depreciation boosts real net exports, inflation expectations are less well anchored than in the $\mathrm{AE}$, and the exchange rate depreciation has large and persistent effects on inflation. This induces the central bank to raise real (and nominal) interest rates, which crowds out domestic demand. Output contracts slightly on balance, while inflation rises substantially clearly highlighting the problems that exchange rate depreciations may pose for economies with these characteristics. Had our simulation allowed for a balance sheet channel in which the exchange rate depreciation increased private borrowing spreads, output would contract even more.

\subsection{Policy Tradeoffs in EMEs}

Our simulations illustrate that EMEs may face difficult policy tradeoffs in the face of shocks that generate large exchange rate movements. Figure 2 compares the effects of the same-sized UIP risk premium shock as in the previous section under two policies. The red-dotted line shows the effects of the benchmark calibration (EME central bank follows a standard Taylor rule, same as in Figure 1) under a more accommodative policy. In this case, the central bank keeps output relatively stable but allows the exchange rate depreciation to have large and persistent effects on both CPI 
Figure 2: Risk-Premium Shocks in Emerging Markets for Alternative Policy Rules.
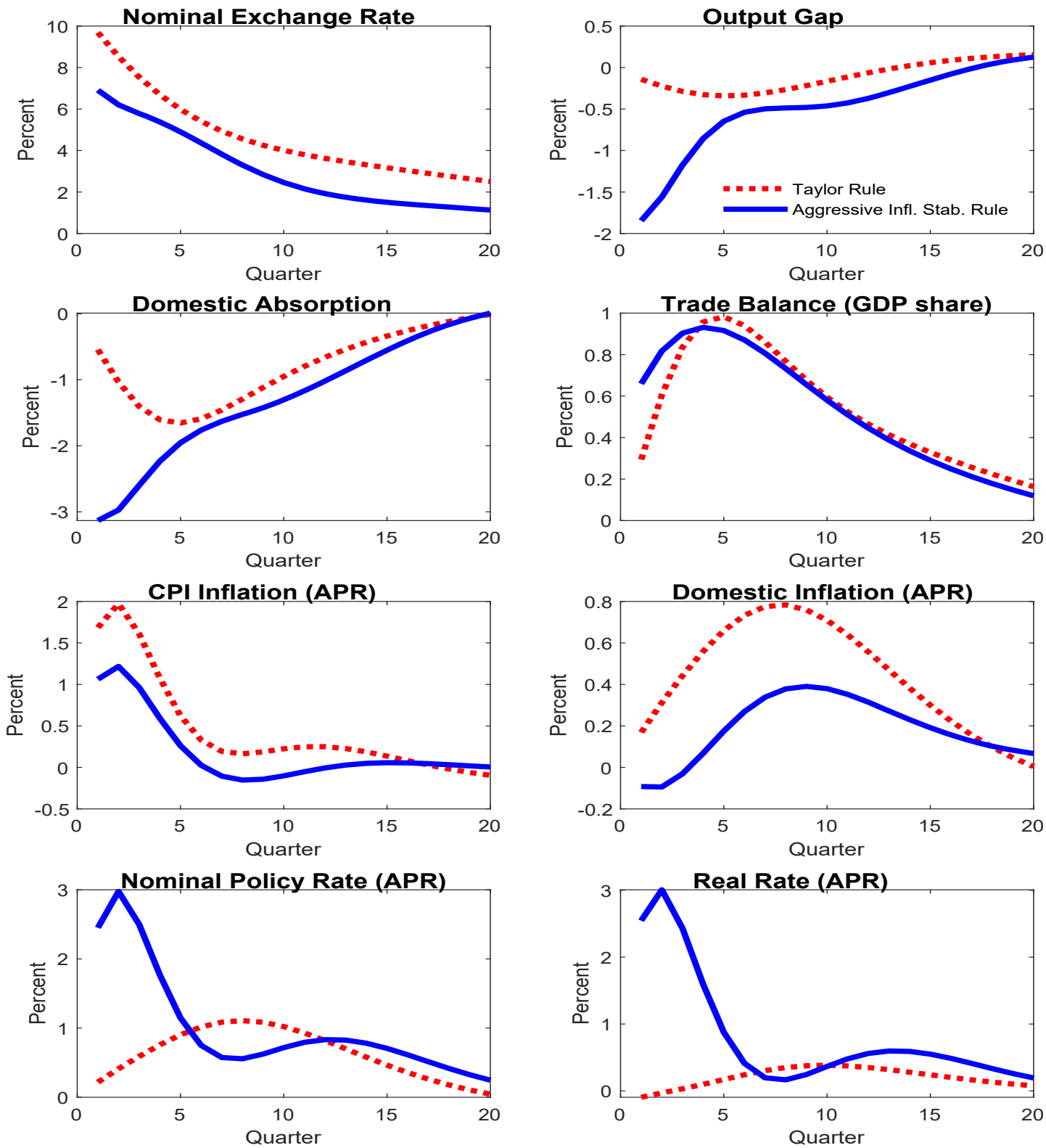

inflation and domestic inflation, potentially undermining monetary policy credibility. By contrast, tighter policy (blue lines) - in which the central bank responds more vigorously to both domestic and imported inflation - limits the size and persistence of the increase in inflation but generates a sharper output contraction of about 1.5 percent.

These scenarios illustrate that conventional monetary policy performs rather poorly in simulta- 
neously achieving a central bank's inflation and output objectives if inflation expectations are not well-anchored. This provides a rationale for using additional policy instruments (FX intervention or capital controls) to reduce the risk of a de-anchoring of inflation expectations, and thereby allowing monetary policy to focus more on output stabilization and improving output-inflation trade-offs.

\section{Shock Transmission in the Nonlinear Model}

Figure 3: Risk Appetite and Risk Premiums

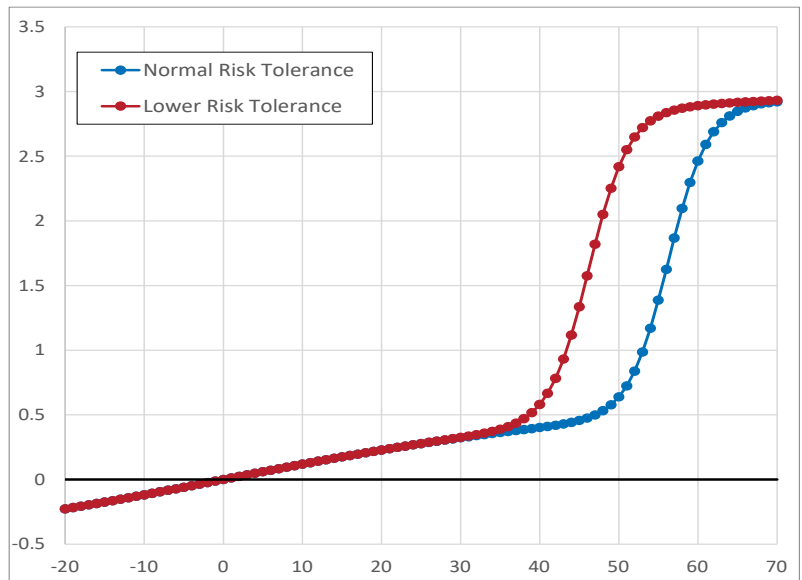

(a) UIP Risk Premium (APR) as a Function of Net Foreign Liabilities

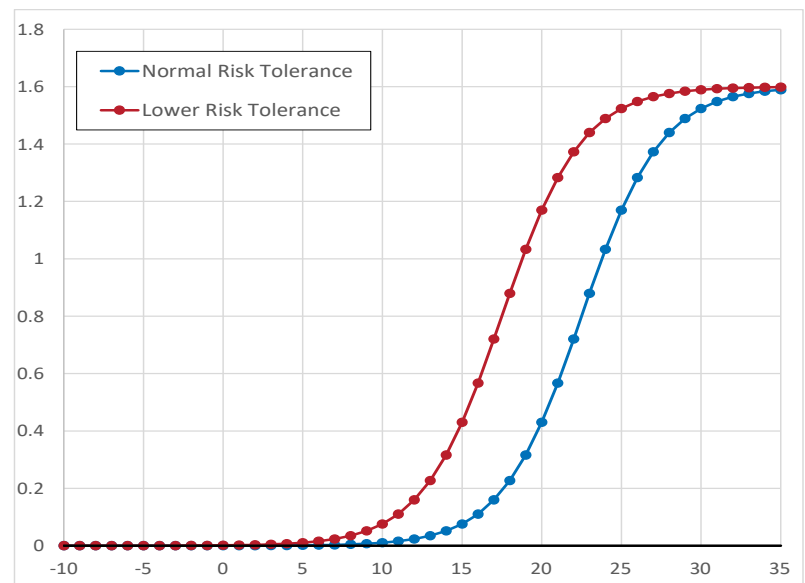

(b) Private Borrowing Spread (APR) as a Function of the Real Exchange Rate

We now turn to simulations in which the nonlinear features of the model environment - including the UIP risk premium and the private borrowing spread - are allowed to play a key role. Broadly speaking, these nonlinear channels aim to capture how economies with weak initial conditions, including a high level of net foreign liabilities and unhedged foreign currency-denominated debt, are more vulnerable to shocks.

While we discuss these nonlinear features more precisely below, Figure 3 provides helpful intuition by illustrating how the UIP risk premium $\Phi\left(d_{t}, \bar{d}_{t}, b_{t}\right)$ is linked to the level of net foreign liabilities $d_{t}$. The blue dotted line illustrates an environment with relatively high risk tolerance, which is captured by a high value of $\bar{d}_{t}$ in our model, and shows that the UIP risk premium only 
rises modestly as net foreign liabilities increase. However, the risk premium jumps much more for highly indebted economies during periods of market stress in which risk tolerance declines, as captured by the red dotted line.

This simple framework captures a key empirical observation from crisis episodes: in the runup to a crisis, spreads are often low even for economies with high vulnerabilities but spreads in vulnerable economies rise sharply during the crisis once risk tolerance declines. This pattern was apparent, for instance, around the time of the euro area sovereign debt crisis as well as during the recent COVID crisis. $^{8}$

\subsection{Modeling of Endogenous Risk-Premiums}

We next provide an overview of how we parameterize the endogenous risk-premiums, $\Psi_{t}=f\left(q_{c, t}\right)$ in eq. (8) and $\Phi\left(d_{t} / \bar{d}_{t}, \phi_{t}\right)$ in eqs. (9) and (10). For $\Psi_{t}$, we specify the following logistic functional form

$$
\Psi_{t}=\rho_{\Psi} \Psi_{t-1}+\mu_{t}+\tilde{\mu}, \mu_{t}=\frac{\mu}{1+e^{-k_{q}\left(q_{c, t}-\bar{q}_{t}\right)}}
$$

where $\bar{q}_{t} \equiv \bar{q}+\varepsilon_{\bar{q}, t}$ is a threshold real exchange rate level $\left(\mathbb{E}\left(\bar{q}_{t}\right)=\mathbb{E}\left(\bar{q}+\varepsilon_{\bar{q}, t}\right)=\bar{q}\right)$ for which the endogenous risk premium becomes elevated, $\mu$ is the maximum one-period increase in the risk-premium $\Psi_{t}, k_{q}$ is the logistic parameter which governs the extent to which the weaker real exchange rate elevates $\Psi_{t}$ contemporaneously when the actual exchange rate approaches $\bar{q}_{t}$. The calibration of $\bar{q}=22.5$ implies that even a substantial real exchange rate depreciation relative to the steady state will not induce much of a rise in the private borrowing spread unless the stochastic risk appetite shock $\varepsilon_{\bar{q}, t}$ is also sufficiently negative so that $\bar{q}_{t} \leq q_{c, t}$. This feature helps match empirical evidence for EME corporate spreads which suggests that although large exchange rate depreciations make a sharp runup in private borrowing spreads (proxied empirically by corporate spreads) more

\footnotetext{
${ }^{8}$ The next subsection presents a technical discussion of how we have calibrated the nonlinear risk premium functions. However, readers not interested in these aspects may skip to the results in Section 4.2.
} 
likely, it is nevertheless often the case that the exchange rate may depreciate substantially without triggering a big increase in spreads.

We now turn to discuss the nonlinear formulation of the UIP risk premium. We assume that $\Phi\left(d_{t}, \bar{d}_{t}, b_{t}\right)$ follows

$$
\Phi_{t}=\rho_{\Phi} \Phi_{t-1}+\tilde{\phi}_{t}, \tilde{\phi}_{t}=\frac{\phi}{1+e^{-b_{t}-k_{d}\left(d_{t}-\bar{d}_{t}\right)}}-\frac{\phi / 2}{1+e^{\frac{k_{d}}{10} d_{t}}}+\tilde{\phi}
$$

where $\bar{d}_{t} \equiv \bar{d}+\varepsilon_{\bar{d}, t}$, is a threshold net foreign liability level $\left(\mathbb{E}\left(\bar{q}_{t}\right)=\mathbb{E}\left(\bar{q}+\varepsilon_{\bar{q}, t}\right)=\bar{q}\right)$ for which the UIP risk premium becomes more sharply elevated, and the constant $\tilde{\phi}$ ensures that the UIP risk premium $\Phi_{t}$ equals 0 in the deterministic steady state. ${ }^{9}$ Foreign asset purchases by the central bank, $b_{t}$, follow an $\mathrm{AR}(1)$ process

$$
b_{t}=\rho_{b} b_{t-1}+\varepsilon_{b, t},
$$

Similarly, the debt appetite/limit, shock follows an AR(1) process satisfying:

$$
\varepsilon_{\bar{d}, t}=\rho_{\bar{d}} \varepsilon_{\bar{d}, t}+u_{\bar{d}, t} .
$$

As can be seen from comparing the two risk premium functions in Figure 3, two key differences between the specification of the private and UIP risk premiums are that the latter is associated with a non-zero slope even when $d_{t}$ is zero and that $\Phi_{t}$ can be negative when the country accumulates foreign assets on net (so that $d_{t}<0$ ). This feature of the UIP risk premium is required to ensure stationary net foreign liabilities, i.e. prevent the small open economy from accumulating infinite net foreign assets (see e.g. Schmitt-Grohe and Uribe, 2003).

We calibrate the parameters pertaining to the endogenous spread functions through the un-

${ }^{9}$ This is achieved by setting $\tilde{\phi}$ in eq. (29) equal to $\frac{\phi / 2}{2}-\frac{\phi}{1+e^{k} d^{\bar{d}}}$. Similarly, the private borrowing spread function (28) contains a $\tilde{\mu}$ parameter which is set so that $\Psi_{t}=0$ in the deterministic steady state. 
conditional stochastic simulations reported in Section 4.3. This procedure, essentially a simulated method of moments exercise (see e.g. McFadden, 1989), enabled us to consider a constellation of the parameters $\rho_{\Phi}, k_{d}, \bar{d}, \phi$, and the $\mathrm{AR}(1)$ process parameters $\rho_{\bar{d}}$ and $\varepsilon_{\bar{d}, t}$ which roughly matches a number of moments (unconditional persistence, unconditional and conditional volatilities, and mean and max values) for sovereign yield spreads on dollar denominated bonds for a selected set of emerging market economies. We adopt the same framework to pin down the key parameters $\left(\rho_{\psi}\right.$, $\left.\mu, \bar{q}, k_{q}\right)$ governing the evolution of private borrowing spreads, here proxied by corporate spreads from JP Morgan's EMBI database, for the same set of EM economies. This procedure leads us to use the following parameter values for the UIP risk premium: $\rho_{\Phi}=.85, k_{d}=.4, \bar{d}=12.5, \phi$ $=.6$, and $\rho_{\bar{d}}=.85$ and $\sigma_{\bar{d}}=11$. For the private borrowing spread, we choose the parameters $\rho_{\psi}$ $=.85, \mu=.4, \bar{q}=22.5, k_{q}=.4$. Even though the real exchange rate and net foreign liabilities are positively correlated in our model (ceteris paribus, countries with higher net foreign liabilities need a weaker exchange rate in order to maintain a persistent trade surplus which improves their external debt position), we allow the shock $\varepsilon_{\bar{q}, t}$ in the private borrowing spread to be influenced by the debt limit shock $\varepsilon_{\bar{d}, t}$ to strengthen the correlation between private and country borrowing spreads. Even so, the median correlation between corporate and sovereign spreads in our sample of EME countries is only about 0.4 , and we therefore assume that the private debt limit shock $\varepsilon_{\bar{q}, t}$ also has an idiosyncratic component, so that

$$
\begin{aligned}
\varepsilon_{\bar{q}, t} & =\varepsilon_{p, t}+\frac{1}{2} \varepsilon_{\bar{d}, t}, \\
\varepsilon_{p, t} & =\rho_{p} \varepsilon_{p, t-1}+u_{p, t}
\end{aligned}
$$

where we set $\rho_{p}=.85$ and $\sigma_{\bar{d}}=4 .^{10}$

\footnotetext{
${ }^{10}$ The unweighted mean of the individual country correlations is slightly lower than the median (.31 instead of .39). These numbers are based on quarterly data on corporate and sovereign spreads from JP Morgan for the following economies: Brazil, Chile, China, Colombia, India, Indonesia, Hungary, Malaysia, Mexico, Peru, Philippines, Poland,
} 
Finally, we motivate why our nonlinear formulation of these spreads plays a crucial role in our framework. One way to do this is to linearize the two risk premiums. The linearized representation of the private borrowing spread in eq. (28) is given by

$$
d \Psi_{t}=\rho_{\Psi} d \Psi_{t-1}-\mu\left(\frac{1}{1+e^{k_{q} \bar{q}}}\right)^{2} e^{k_{1} \bar{q}}\left(-k_{q}\left(d q_{c, t}-d \varepsilon_{\bar{q}, t}\right)\right)
$$

and so, using the fact that $q_{c}=1$ so $d q_{c, t}=q_{c, t}, \mathbb{E}\left(\varepsilon_{\bar{q}}\right)=0$, and exploiting that $\Psi=0$ so $d \Psi_{t}=\psi_{t}$, we arrive at

$$
\psi_{t}=\rho_{\Psi} \psi_{t-1}+\rho_{q}\left(q_{c, t}-\varepsilon_{\bar{q}, t}\right)
$$

Comparing equations (28) and (33), we can observe that the effective coefficient on the real exchange rate in a linearized approximation of the nonlinear model, i.e. $\rho_{q} \equiv \mu \frac{e^{k_{q} \bar{q}}}{\left(1+e^{k_{q} \bar{q}}\right)^{2}} k_{q}$, will be a very small number (under our calibration $\rho_{q} \approx 2 \mathrm{e}-5$ ). One important implication is that capturing the empirically relevant nonlinearities of private borrowing spreads would seem infeasible in a standard linearized DSGE framework.

Turning to the country-specific UIP risk premium $\Phi_{t}$ in (29), total differentiation gives

$$
d \Phi_{t}=\rho_{\Phi} d \Phi_{t-1}+\phi\left(\frac{1}{1+e^{k_{d} \bar{d}}}\right)^{2} e^{k_{d} \bar{d}}\left[d b_{t}+k_{d}\left(d d_{t}-d \varepsilon_{\bar{d}, t}\right)\right]+\frac{\phi}{2}\left(\frac{1}{2}\right)^{2} \frac{k_{d}}{10} d d_{t}
$$

As $\Phi=0$ we have that $d \Phi_{t}=\phi_{t}$ and since $d b_{t}=b_{t}, d d_{t}=d_{t}$ and $d \varepsilon_{\bar{d}, t}=\varepsilon_{\bar{d}, t}$, the above equation implies

$$
\phi_{t}=\rho_{\Phi} \phi_{t-1}+\phi_{d} d_{t}+\phi_{b} b_{t}-\phi_{\varepsilon_{\bar{d}}} \varepsilon_{\bar{d}, t}
$$

where we have defined $\phi_{d}=\phi k_{d}\left[\left(\frac{1}{1+e^{k} d^{\bar{d}}}\right)^{2} e^{k_{d} \bar{d}}+\frac{1}{80}\right], \phi_{b}=\phi\left(\frac{1}{1+e^{k_{d} \bar{d}}}\right)^{2} e^{k_{d} \bar{d}}$ and $\phi_{\varepsilon_{\bar{d}}}=\phi_{b} k_{d}$.

Russia and Turkey. For most countries the sample runs from early 2000 until last quarter in 2019, but for India and Hungary data are only available from late 2012. However, both the mean and median correlation between corporate and sovereign spreads are basically unchanged if India and Hungary are excluded from our sample. 
Now, given our parametrization of the nonlinear risk premium, these parameters are quite small $\left(\phi_{d}=.003, \phi_{b} \approx 1 \mathrm{e}-10\right.$, and $\left.\phi_{\varepsilon_{\bar{d}}} \approx 4 \mathrm{e}-11\right)$. This implies that exogenous risk premium shocks $\varepsilon_{\bar{d}, t}$ and the central banks' foreign asset purchases/sell-offs $b_{t}$ would have very limited effects on the risk premium if this relationship was log-linearized. In economic terms, our reduced form is consistent with a central implication of the microfounded model by Chang (2019), namely that FXIs have essentially no effect on the UIP risk premium in normal times, but can have substantial effects when investor risk tolerance is low (consistent with global financial stress) and the economy has weak initial conditions.

\subsection{Effects of FXI in a Crisis Situation}

We consider a scenario where an adverse external shock in global risk tolerance - captured by a reduction in $\bar{d}_{t}$ - is coupled with a fall in foreign import demand $c_{t}^{*}$. To highlight how initial conditions influence transmission, we compare the case of a "vulnerable EME" economy that has a high level of net foreign liabilities with that of a "less vulnerable EME" with a low level of net foreign liabilities. While we assume that both shocks are identical, the decline in global risk tolerance engenders a much sharper rise in the UIP risk premium $\Phi_{t}$ in the more heavily indebted vulnerable EME (as suggested by Figure 3 above). We assume that the shock to $\bar{d}_{t}$ follows an $\operatorname{AR}(1)$ with a persistence of .85 , and hence has a half-life of about 5 quarters.

Figure 4 shows that the vulnerable EME experiences a depreciation of its real exchange rate that is several times larger than in the less vulnerable EME. While the depreciation provides a larger boost to net exports in the vulnerable EME, its output nonetheless experiences a considerably larger contraction. The bigger output decline both reflects that the depreciation triggers a larger rise in private borrowing spreads, and that the larger rise in inflation in the vulnerable EME requires monetary policy to be much tighter than in the less vulnerable EME. 
Figure 4: Drop in Risk Appetite and External Demand in EMEs with Different FX m

Figure 4: Drop in Risk Apetite and External Demand in EMEs with Different FX Exposure.
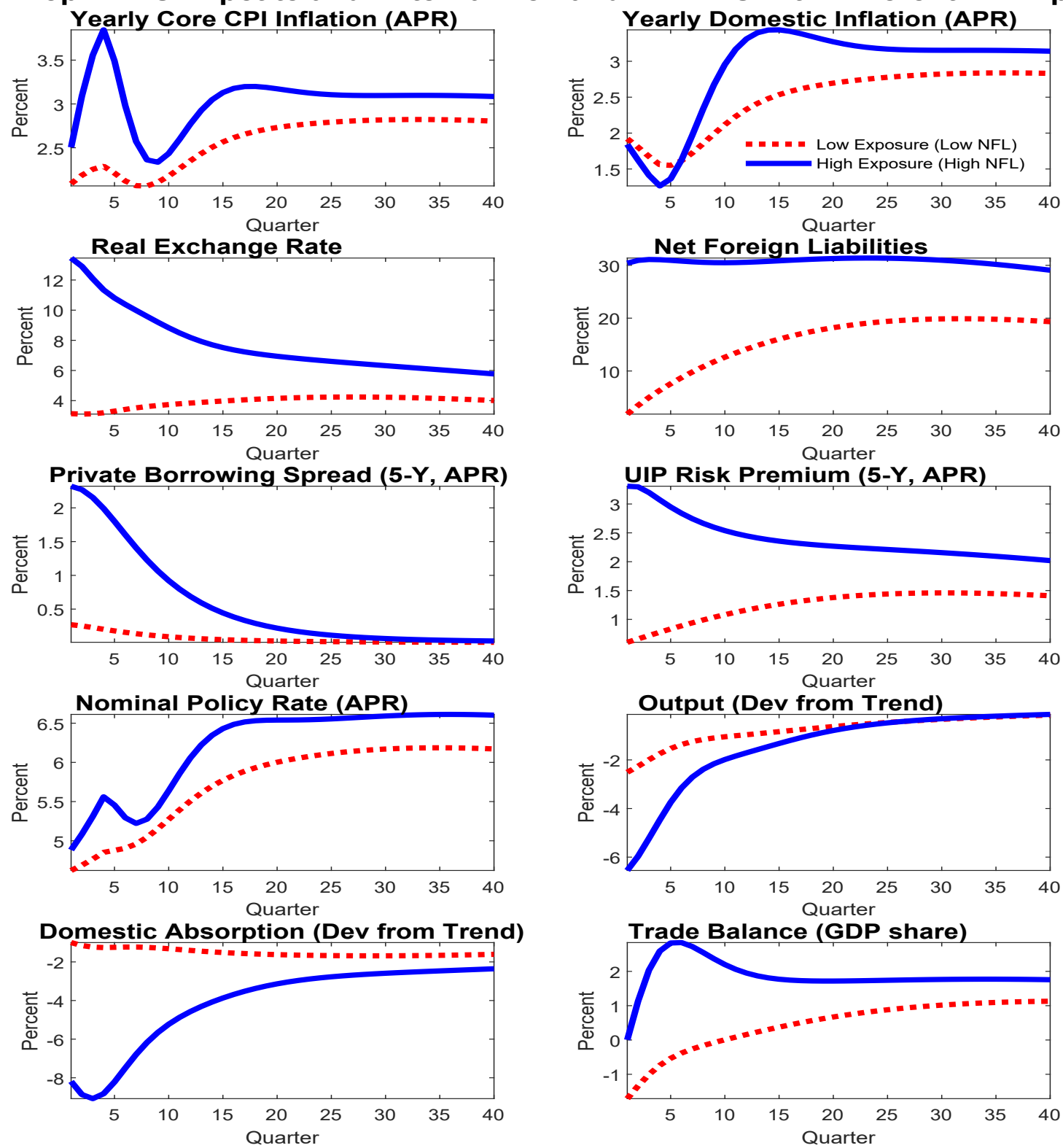

The confluence of a larger output contraction and substantially higher inflation in the vulnerable EME in response to these common shocks captures a familiar policy dilemma facing EME policymakers. Sharper monetary policy tightening in the vulnerable EME could reduce inflation, but, as we have seen, would cause a much larger decline in output. While the poorer tradeoff for the more vulnerable EME is driven by the larger exchange rate depreciation - and thus due 
to weaker initial conditions - the disparity between the EMEs would be even larger if we allowed for structural differences such as less well-anchored inflation expectations in the more vulnerable EME.

Figure 5: Effects of FXI and CFM in Adverse Scenario for EME With High FX Debt.
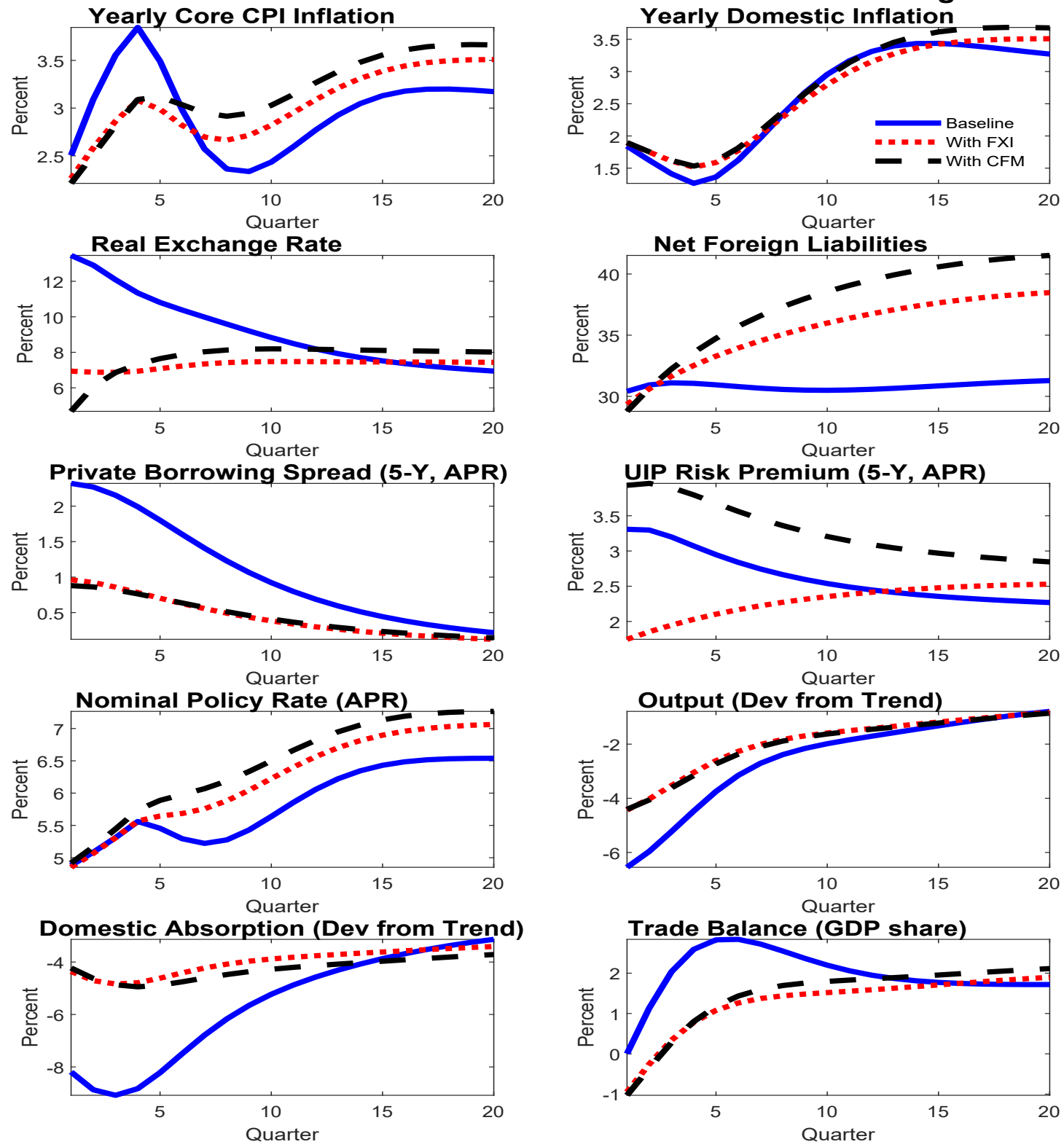

Accordingly, we next consider how FXI or capital flow management (CFM) tools could improve the policy frontier of the vulnerable EME. In this vein, Figure 5 compares the effects of the same 
shock to $\bar{d}_{t}$ under the baseline Taylor rule (the solid blue lines - as in Figure 4) to cases in which the authorities also utilize FXI sales (the red dotted lines) or use CFMs to raise the tax on capital outflows $\tau_{t}$. Either of these policies reduces the depreciation of the exchange rate, which allows policy to be more accommodative by lessening inflationary pressure, and also mitigates the rise in private borrowing spreads. ${ }^{11}$ The upshot is that these policies allay the "stagflationary" effects of the UIP risk premium shock, reducing inflation while boosting output and exerting even larger expansionary effects on domestic demand (since real net exports improve less).

In the medium-run, the stronger exchange rate and domestic demand under FXIs or CFMs translate into less trade balance improvement, and, consequently, a somewhat bigger deterioration of net foreign liabilities. The higher net foreign liabilities in turn account for why the UIP risk premium runs a bit higher in the longer-run under these policies than under the baseline, which also translates into a bit weaker exchange rate. The upward pressure on the UIP risk premium is slightly higher for CFMs than FXIs given that the latter directly depress the risk premium and hence the cost that home residents face of borrowing in dollars, whereas CFMs do not (instead, they make domestic assets more attractive by raising their after-tax rate of return).

While there is some intertemporal tradeoff in using these tools, their ability to improve nearterm inflation-output tradeoffs makes them appealing in the case of fairly transient shocks to $\bar{d}_{t}$. Their appeal is somewhat diminished, however, as the shock becomes more protracted. While CFMs and FXIs still improve output-inflation tradeoffs in the near-term, they weaken the turnaround in domestic borrowing that is needed to lower risk spreads in the longer-term. Because investor risk appetite remains low, risk spreads run considerably higher at longer-horizons, pushing output below the level that would prevail absent such interventions and inflation higher.

In addition to improving tradeoffs in episodes of financial tightening, these policies may play an

\footnotetext{
${ }^{11}$ Policy rates behave very similarly across the scenarios, reflecting that while FXI and CFMs reduce inflationary pressure - and thus have the partial effect of allowing for easier policy - they also boost output, which calls for tighter policy under the Taylor rule.
} 
insurance role by limiting an endogenous buildup of risk associated with higher foreign indebtedness. This may be achieved by responding to "favorable" risk premium shocks (associated with surging capital inflows) that cause the exchange rate to appreciate and private borrowing spreads to fall. In terms of Figure 3, it means keeping the economy away from high debt levels that make the economy vulnerable to a sudden sharp rise in spreads akin to that just explored. Even so, this insurance does come at some cost: in particular, such policies preclude some of the borrowing that would benefit households if the high global risk tolerance state were to persist.

\subsection{Unconditional Distributions}

We now analyze the implications of the nonlinear risk premiums for the unconditional distributions, and consider how policy actions - including a state-contingent rule for adjusting foreign exchange interventions or capital controls - can potentially improve outcomes.

As a prelude to our results, we first describe the setup of our simulations. Importantly, we do not include any FXI or CFM measures initially in order to consider probability distributions when the central bank only uses the nominal policy rate for macroeconomic stabilization. Specifically, we assume six exogenous shocks driving macroeconomic fluctuations: these include variations in private consumption $\left(e_{c, t}\right)$, government spending $\left(g_{t}\right)$, foreign demand $\left(c_{t}^{*}\right)$, monetary policy shock ( $e_{i, t}$ in equation 26), the sovereign risk premium/debt limit shock $\left(\varepsilon_{\bar{d}, t}\right.$ in equation 31$)$, and the private risk premium/debt limit shock $\left(\varepsilon_{\bar{q}, t}\right.$ in equation 32$)$. The $e_{c, t}, g_{t}, c_{t}^{*}$ and $e_{i, t}$ shocks all follow $\operatorname{AR}(1)$ processes with root .95 , with the exception of $e_{i, t}$ for which $\rho_{i}=.8 .{ }^{12}$ The shock standard deviations are set to $1.5\left(e_{c, t}\right.$ and $\left.g_{t}\right), 2$ for $c_{t}^{*}$, and to $0.25 / 4$ for the monetary policy shock (so

0.25 at an annualized rate). The calibration of the risk-premium shocks $\varepsilon_{\bar{d}, t}$ and $\varepsilon_{\bar{q}, t}$ are kept at the values discussed previously in Section 4.1. Finally, as our model does not feature any steady-state

\footnotetext{
$\overline{12}$ This somewhat lower root for $e_{i t}$ is sufficient to generate a persistent policy rate.
} 
values for either the private or country-specific spreads, we add the median spreads observed in our EM economies (117 basis points for corporates and 205 basis points for the government) to the simulated data for these variables. We do this to test whether our risk premium specifications are reasonable and do not generate sharply negative sovereign spreads when measured in levels.

Figure 6: Relationship Between UIP Risk Premium and Private Borrowing Spread
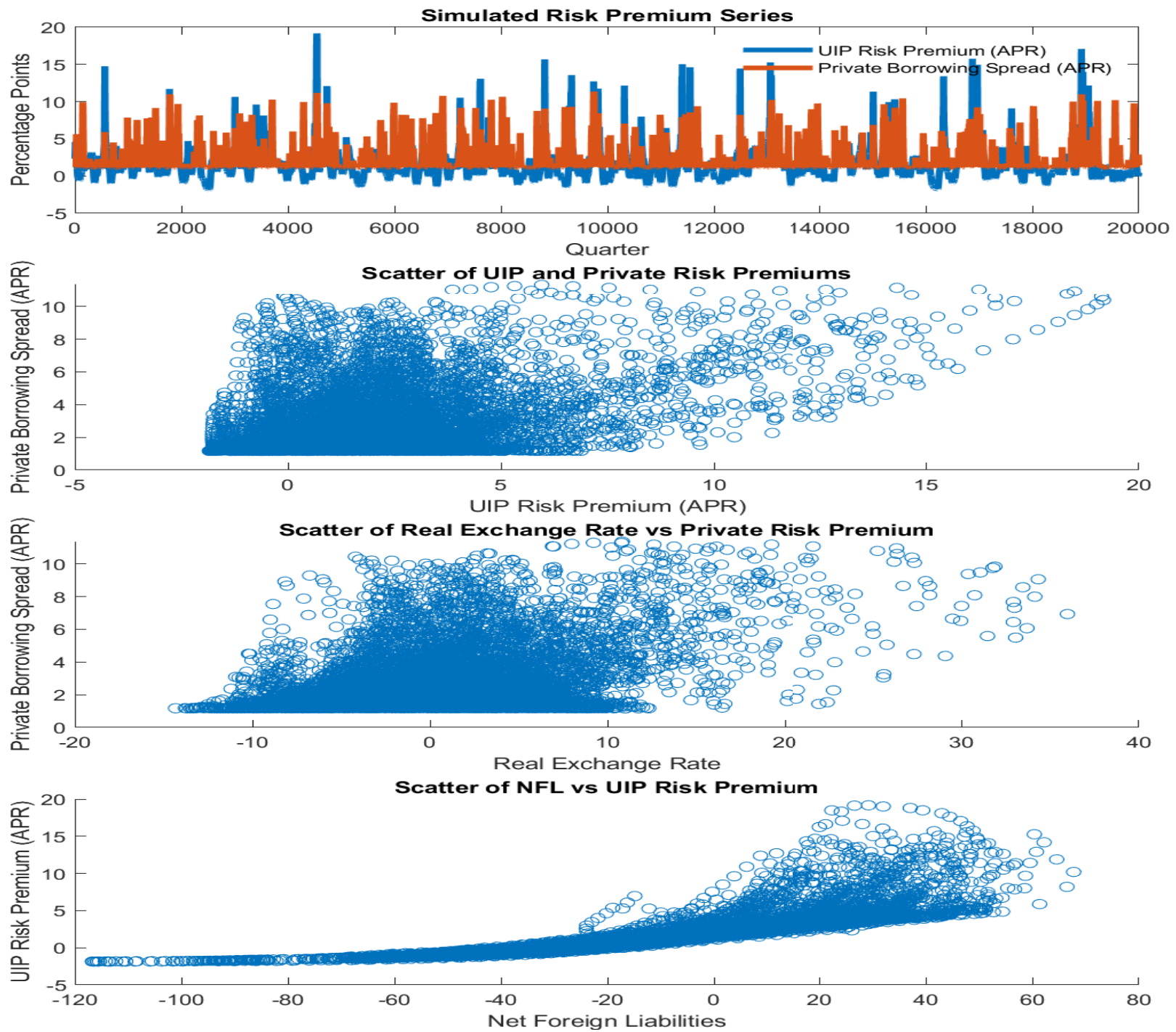

Equipped with these shock processes, we simulate a long-sample of $T=20,000$ observations. It is helpful to compare both the linearized and nonlinear model using the perfect foresight algorithm in Dynare. Importantly, the shocks we sample are identical for both models, so that any differences 
in the resulting simulated distributions reflect differences in shock propagation mechanisms, i.e. the nonlinear risk premiums in equations (28) and (29).

Figure 6 shows simulated data from the model to illustrate linkages between key financial variables. The top panel simply shows the simulated time series for the two risk premium series (in annualized percentage points). The second and third panels provide scatter plots showing that private borrowing spreads tend to rise when the UIP risk premium rises (second panel), or, alternatively, when the real exchange rate depreciates (third panel). However, consistent with the data, the relationship is not particularly tight. ${ }^{13}$ Finally, the scatter plot in the bottom panel shows that the chances of an elevated UIP risk premium are low if the economy has a favorable net foreign asset position, but become much more elevated as net foreign liabilities expand. It is also worth noting that the UIP risk premium sometimes falls slightly below zero to prevent an excessive accumulation of net foreign assets and ensure stationarity.

Figure 7 shows the probability distributions of key model variables. The UIP risk premium has a strong positive skew driven by negative risk-off episodes in the presence of excessive external indebtedness of the home economy. This nonlinearity also implies that the distribution of net foreign liabilities is skewed to the left. Risk-off shocks and the occasional need of the home economy to generate trade surpluses to cover debt service costs trigger a right skew in the real exchange rate, implying that the exchange rate occasionally depreciates substantially to boost the trade balance and to pay off debt, thereby stabilizing sovereign risk premiums.

While the exchange depreciation may help improve the home external balance, it may also depress domestic demand by inducing tighter borrowing conditions. This channel is evident in the lower left panels in Figure 7 which show the output gap and domestic absorption. Domestic absorption has a sizeable negative left skew which stretches to -15 percent. The output gap also

\footnotetext{
${ }^{13}$ The unconditional correlation coefficient is 0.35 , which is close to the median value of 0.39 in the data.
} 
Figure 7: Unconditional Distributions in Linearized and Nonlinear Models
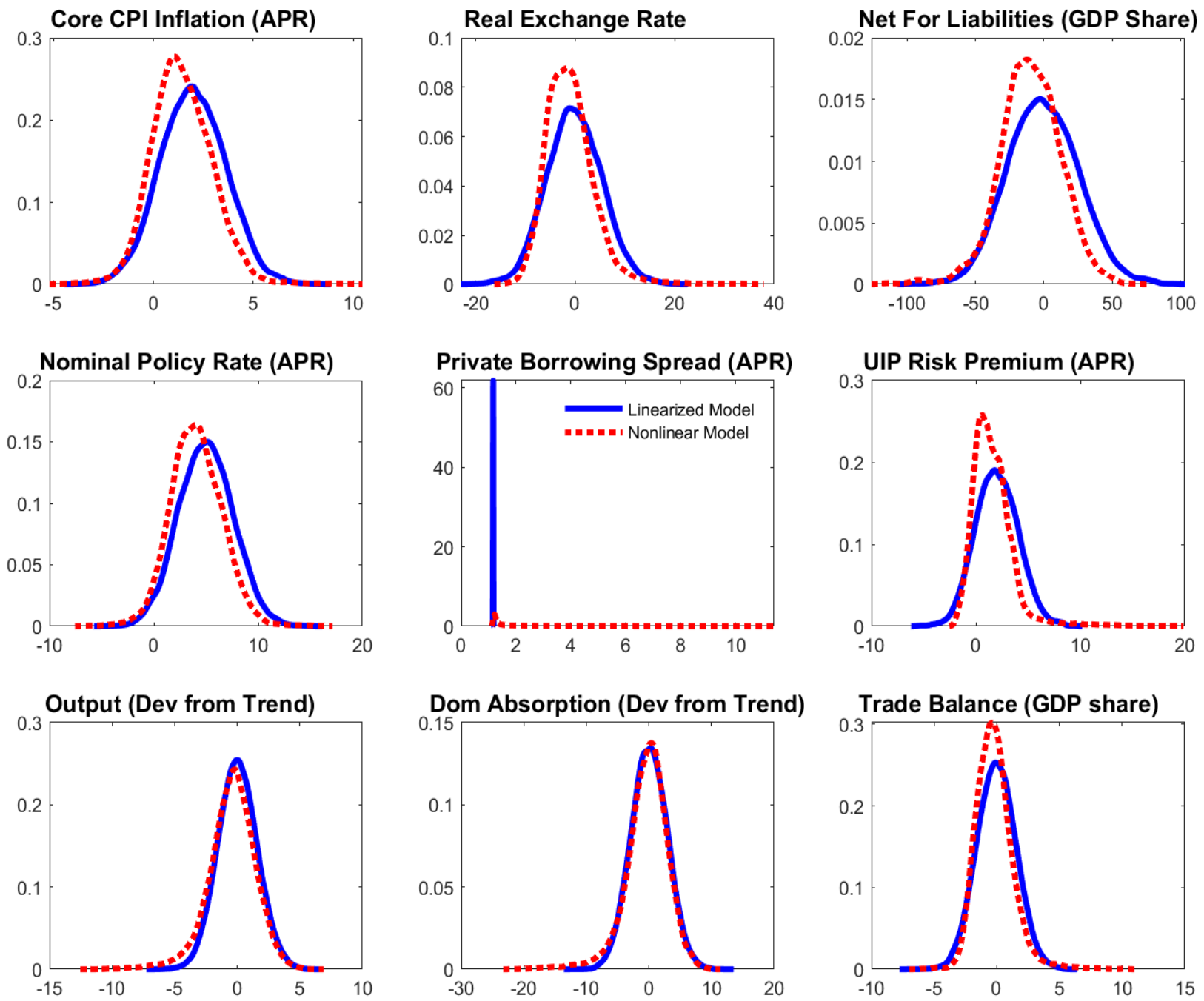

has a sizeable, though somewhat smaller, skew to the left that extends roughly to -10 percent.

The negative skew for the output gap is relatively smaller because the trade balance works as an automatic stabilizer and improves conditions when domestic demand is depressed. The right skews of the real and nominal exchange rate imply that CPI inflation has a longer right tail. Even so, because output is occasionally more depressed in the nonlinear economy due to the elevated private borrowing spreads and UIP risk premium, CPI inflation also has a somewhat more elongated left tail. 


\subsection{FXI and CFM Policy Rules}

We have thus far considered the effects of exogenous changes in FXI and CFMs. We now turn to analyzing policy reaction functions (or "rules") in which the authorities are assumed to adjust FXI and CFMs in a systematic way in response to fluctuations in both the UIP premium $\Phi_{t}$ and private borrowing spread $\Psi_{t}$. Below, we first present the rules considered, and then discuss how they impact the crisis scenario and the unconditional distributions.

We specify slightly different rules for foreign asset purchases $b_{t}$ and outflow CFM measures $\left(\tau_{t}\right)$. The rules are intended to capture the nonlinearities in the behavior of the risk premiums. For asset purchases, we assume the following rule

$$
b_{t}=b_{\mu} \mu_{t}-b_{d}\left(d_{t}-\bar{d}_{t}\right)
$$

where $\mu_{t}$ is the innovation to private borrowing spreads in eq. (28) and $d_{t}-\bar{d}_{t}$ is the key driver of the nonlinearities in the UIP risk premium in eq. (29). The policy parameters $b_{\mu}$ and $b_{d}$ are both positive (so e.g. an increase in $d_{t}$ or decrease in $\bar{d}_{t}$ triggers lower $b_{t}$, i.e. foreign asset sales). Our rationale behind the rule is the central bank intervenes on the foreign exchange market to sell its currency reserves if either private borrowing spreads or the risk-premium on government bonds issued in foreign currency rises. It is important to note that the specification implies that the central does not attempt to offset all fluctuations in the UIP risk premium: the central bank only responds to the part of the premium that depends on the non-fundamental debt limit shock and not the fundamental part that is only driven by net foreign liabilities (i.e. the second term in eq, 29). ${ }^{14}$ In this sense the rule is "minimalistic" and implies that the CB only intervenes when either private or the countries exchange rate premium are off relative to fundamentals and if they

\footnotetext{
${ }^{14}$ Note that the FX intervention rule must react "slightly" to net foreign liabilities $d_{t}$ to ensure the stationarity of the model.
} 
are not the central bank only uses its traditional policy tool (nominal policy rate) for stabilization. As a benchmark parametrization, we set $b_{\mu}=5$ and $b_{d}=k_{d}$ in eq. (35).

Turning to the rule for outflow CFMs $\left(\tau_{t}\right)$, we adopt the following rule

$$
\tau_{t}=\tau_{\mu} \mu_{t}+\tau_{\phi}\left(\tilde{\phi}_{t}-\phi_{t}-\rho_{\Phi} \phi_{t-1}\right)
$$

where $\tilde{\phi}_{t}$ is the innovation to the nonlinear risk premium in eq. (29) and $\phi_{t}-\rho_{\Phi} \phi_{t-1}$ is its linearized counterpart (see eq. 34). The policy parameters $\tau_{\mu}$ and $\tau_{\phi}$ are both positive. Hence, the rule implies that an increase in $\mu_{t}$ triggers an increase in the capital output flow tax to reduce incentives to sell the domestic currency. The rationale behind the second term is that the central bank attempts to use CFMs to change the exchange value of its currency so that the risk premium on government bonds follows its linearized equivalent (which is primarily affected by its net foreign asset position and not the non-fundamental debt limit shock $\varepsilon_{\bar{d}, t}$, see the discussion in connection with eq. 34). Similarly to the rule for $b_{t}$, we set $\tau_{\mu}=5$ and $\tau_{\phi}=2.5$.

In Figure 8, we show the impact full commitment to these rules can have on the equilibrium for a vulnerable EME crisis scenario. ${ }^{15}$ As a reference point, we also report the baseline scenario without any endogenous rules; this baseline is the same as the case with high initial FX exposure discussed in Figure 4. As can be seen from the figure, both policy rules are sufficiently aggressive to deliver efficient stabilization of the private borrowing spreads and a much lower initial path for the UIP risk premium. Even so, as was the case in Figure 5 these interventions delay the adjustment towards lower net foreign liabilities which implies that the UIP risk premium eventually becomes slightly more elevated. So when both private and the UIP risk premium are higher simultaneously, both rules deliver nearly the same outcome. Even so, the lower right box shows that the two rules

\footnotetext{
${ }^{15}$ An implicit assumption is of course that the central bank has sufficient reserves and determination to follow-through on the rules.
} 
may imply very different concrete policy actions. Specifically, very small adjustments are needed for outflow CFMs according to our model if a rule clarifying how they will be adopted is credibly communicated.

Fioure 8: FMF, Cricis Srenario in Nonlinear Model w/uro FXT and CFM Rules

Figure 8: EME Crisis Scenario in Nonlinear Model w/wo FXI and CFM Rules.
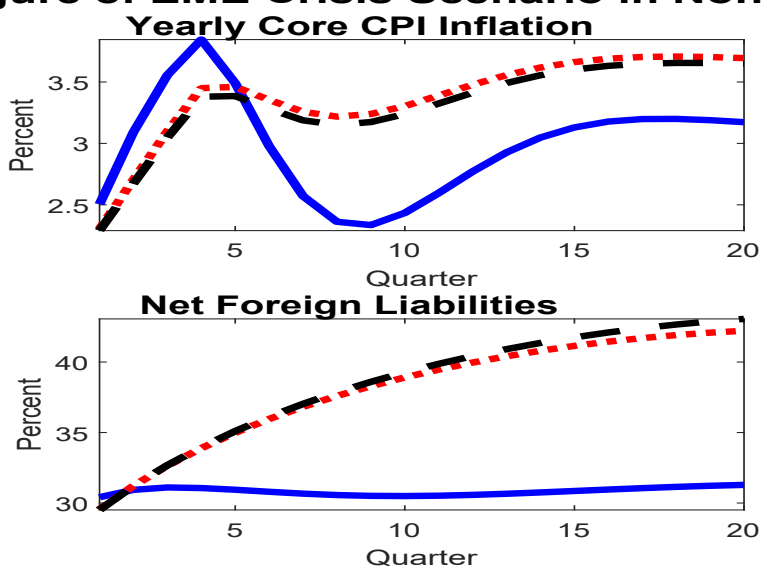

Private Borrowing Spread (APR)
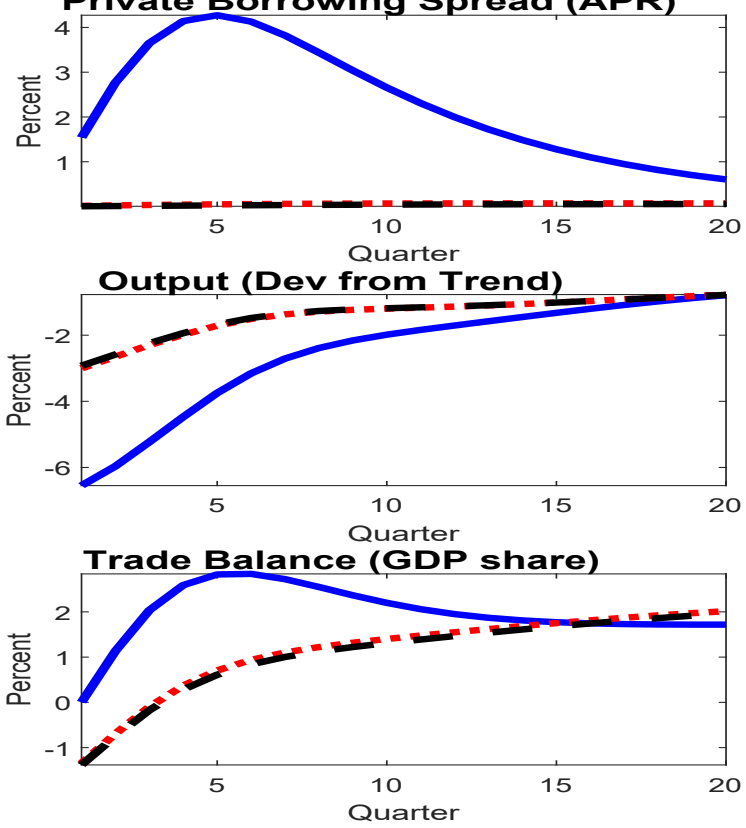
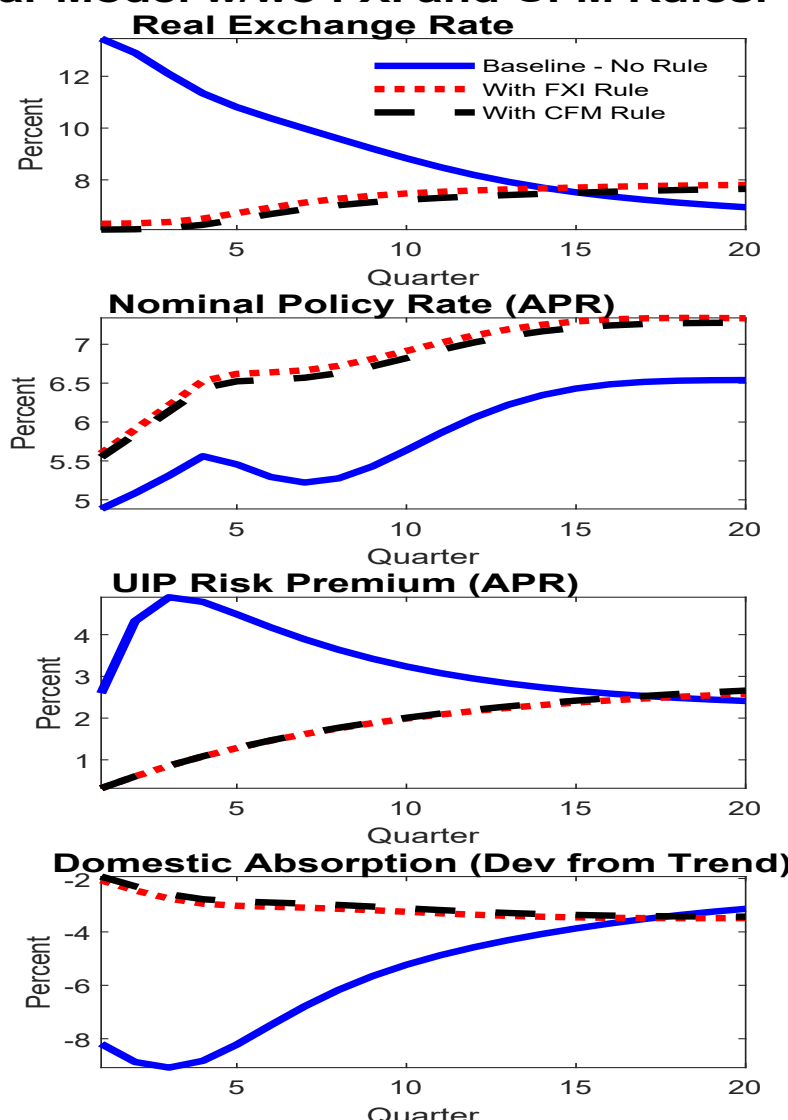

FX Policy Instrument

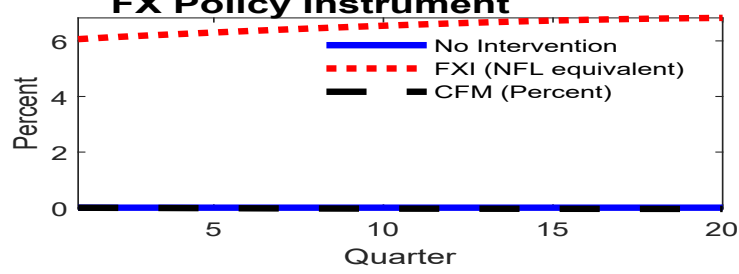

Figure 9 shows how the simulated probability distributions of selected variables in the nonlinear model are affected under a combined FXI/CFM policy rule where FX purchases $\left(b_{t}\right)$ are used to stabilize the UIP risk premium and outflow CFM measures $\left(\tau_{t}\right)$ are used at times to avoid large depreciations and thereby reduce private borrowing spreads. These policy reaction functions are 
Figure 9: Unconditional Distributions in Nonlinear Model w/wo Exchange Rate Rule

Figure 9: Unconditional Distributions in Nonlinear Model w/wo Exchange Rate Rule.
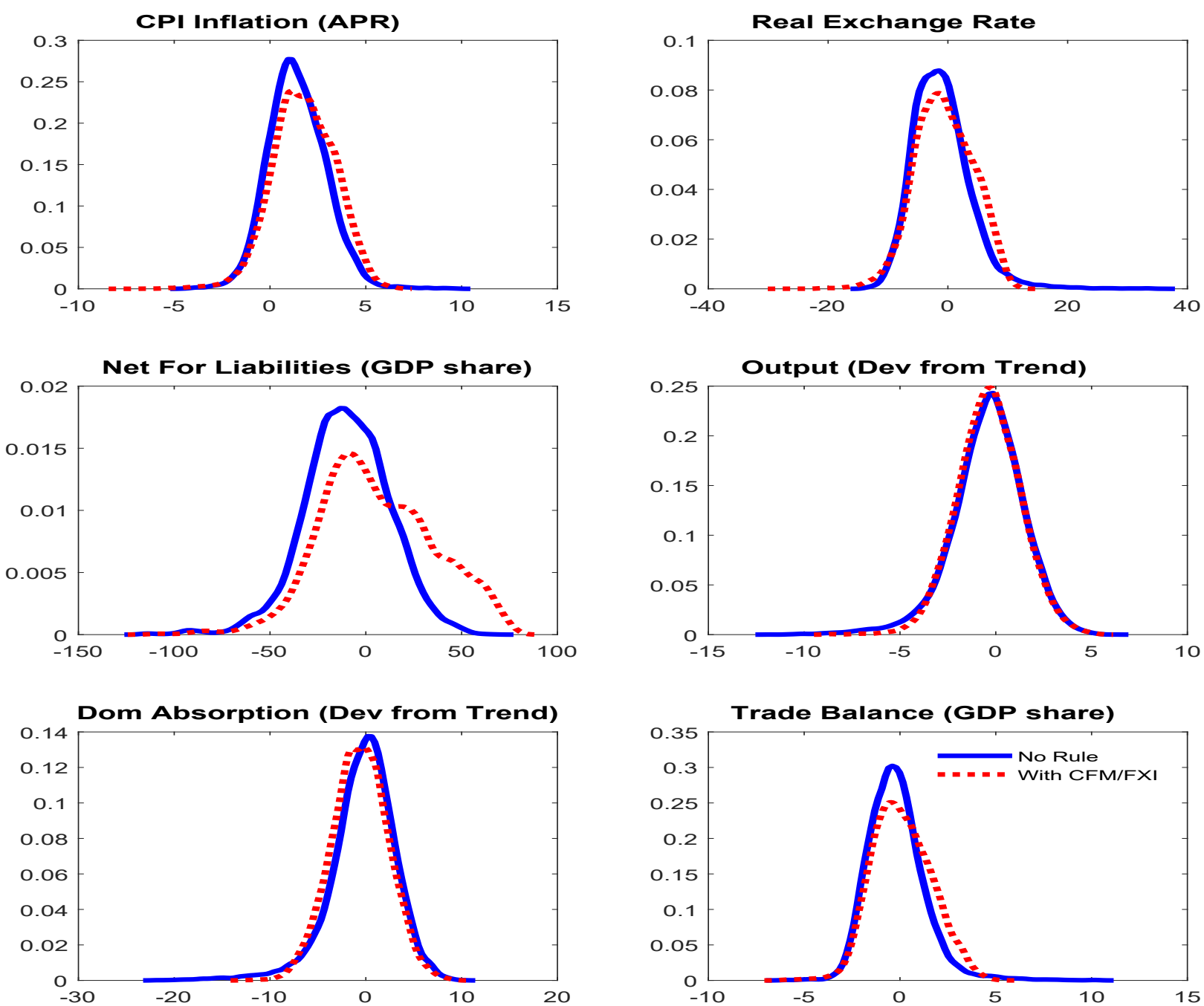

effective in countering some of the effects of "sudden stop" shocks that induce a rise in the UIP premium and tightening of private borrowing spreads. Notably, these policy rules markedly reduce the likelihood of large real exchange rate depreciations (consistent with the impulse response to these tools shown in Figure 5). This in turn mitigates the rise in private borrowing spreads, and the need for sharp policy tightening to control inflationary pressures. These policy reactions have the effect of noticeably reducing the tail risk of a large output contraction that are often driven by such episodes, and of the large corresponding swings of the trade balance into surplus. 


\section{The Effects of FXI in a Liquidity Trap}

We next consider how FXI can potentially help boost inflation in an economy experiencing low inflation and very limited policy space; for example, this could happen with policy rates hitting an effective lower bound (ELB) and other unconventional policy tools cannot provide sufficient stimulus to stabilize core CPI inflation. Our analysis builds on Svensson's "foolproof way" (Svensson, 2003) whereby FXI can facilitate exit from a liquidity trap by jump starting inflation and reducing real interest rates (as well as boosting external competitiveness). For this exercise, we consider an advanced economy, and simply use the linearized version of the model with the private spread and UIP risk premium shocks set to zero; but the qualitative implications are similar for EMEs as noted below.

To construct our baseline, we follow the fiscal multiplier literature (e.g. Christiano et al., 2011; Erceg and Linde, 2014) and assume that the economy is hit by a mix of large adverse global and domestic shocks that trigger a deep recession and drive the nominal interest rate to zero (the assumed lower bound). The particular shocks we consider are negative realizations of the consumption preference shock $e_{c, t}$, and export demand $c_{t}^{*}$ that follow $\operatorname{AR}(1)$ processes with root 0.95. We also assume a positive risk appetite shock $\bar{d}_{t}$ (i.e. flight to safety flows) which puts appreciation pressure on the exchange (this shock follows an $\operatorname{AR}(1)$ process with root 0.85$).{ }^{16}$ Against this backdrop in which output and inflation are well below their target levels, the central bank purchases FX, so $b_{t}>0$ in UIP equation (9), to boost inflation and economic activity. The variable $b_{t}$ follows an $\mathrm{AR}(1)$ process with the same persistence as the debt appetite shock $\bar{d}_{t}$ (i.e. 0.85) to capture an intervention in the currency market which provides a persistent yet transient depreciation of the home currency.

Figure 10 presents the results for the AE calibration of our model. The blue lines show the

\footnotetext{
${ }^{16}$ Erceg and Linde (2014) prove that the results are robust to different types of shocks used to generate the baseline when all the model equations (apart from the policy rule for which the ZLB is imposed) are linearized.
} 
Figure 10: FX Intervention in a Liquidity Trap in Advanced Economies

Figure 10: FX Intervention in a Liquidity Trap in Advanced Economies.
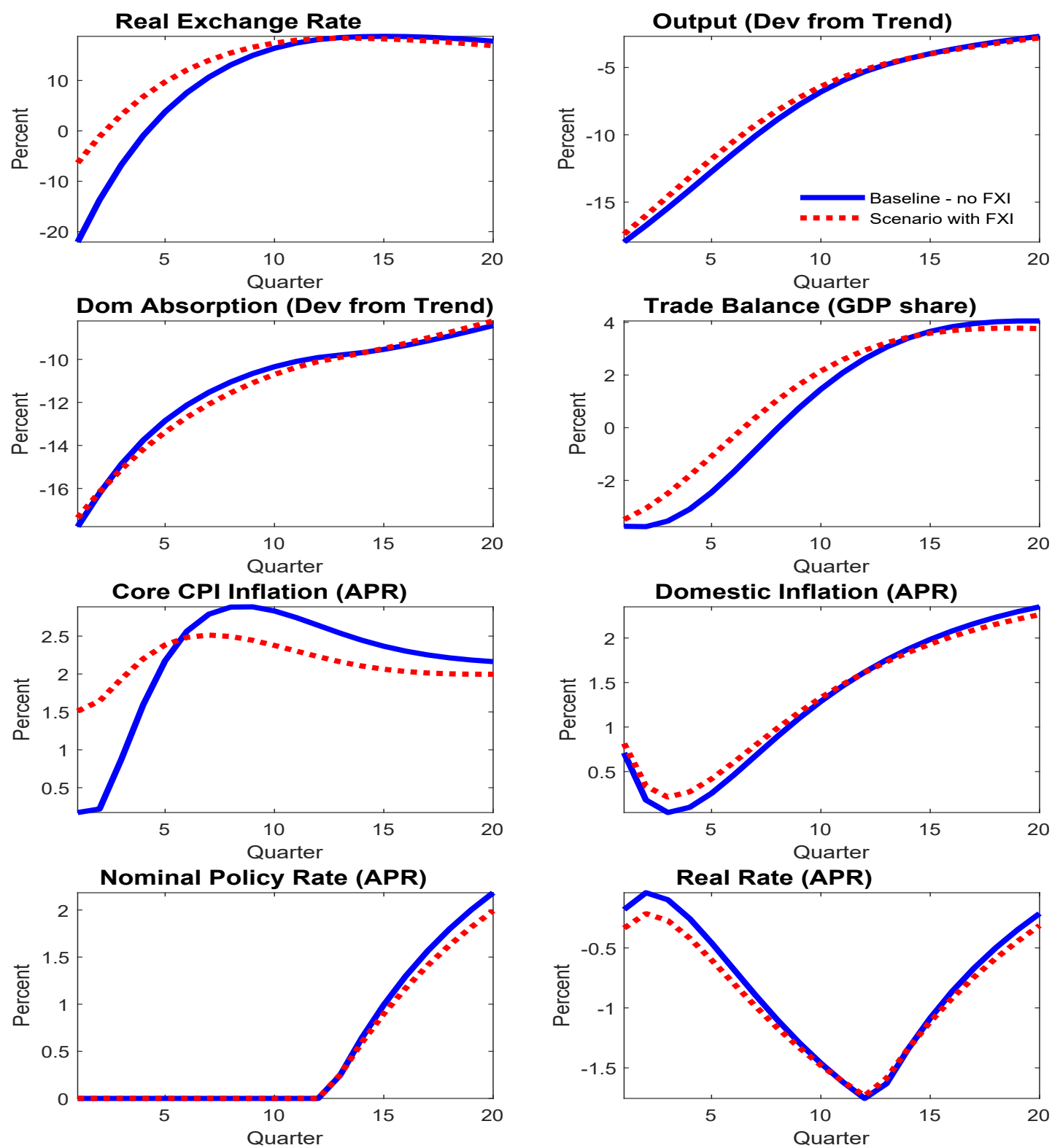

baseline in which the adverse global shocks and weaker domestic demand lead to a deep recession and fall in inflation that is reinforced by domestic currency appreciation. Inflation falls below zero, output falls over 10 percent below baseline, and the policy rate is pinned at zero. The red line shows the effects of a foreign exchange intervention, i.e. of purchases of foreign assets which cause $b_{t}$ to rise. The exchange depreciation induced by the FXI cushion the blow of the recessionary 
shocks by raising net exports and stimulating output. Moreover, because the central bank doesn't react to higher inflation by raising policy rates, real interest rates decline which crowds in domestic demand initially. Furthermore, and importantly, the weaker exchange rate implies that core CPI inflation remains much closer to its 2 percent target during the crisis, implying that the intervention stabilizes both inflation and output better.

Emerging market economies close to their effective lower bound on policy rates and with more responsive inflation expectations may derive even more of a boost to inflation and output through the use of FXIs (or CFMs, which can elicit similar effects). For instance, in the absence of any material effects on either the UIP risk premium or on the private borrowing spread, the same-sized intervention as in Figure 10 has notably larger stimulative effects on domestic absorption and the output gap that are mainly attributable to larger second round effects on inflation. This implies that FX tools may also be useful to alleviate monetary policy tradeoffs stemming from the ELB, at least for EMEs with indebtedness well below the debt limit (i.e., the EME in question is not vulnerable to a risk-off shock).

\section{Conclusion}

In this paper, we have developed a quantitative model for the integrated policy framework (IPF) that is empirically oriented and useful in showing how alternative IPF tools may improve policy tradeoffs and help mitigate downside risks. In particular, economies with less well anchored inflation expectations and significant foreign currency mismatch can potentially benefit from using FXIs or CFMs. We use the nonlinear version of our model to highlight that the potential scope for improving tradeoffs is even stronger for economies with weak initial conditions (such as high debt levels).

We do, however, underscore that additional considerations must be taken into account when 
deciding whether or not to utilize these tools in practice, including the potential longer-term costs of these policies. In this vein, the use of FXIs and CFMs - especially if frequent - may slow the development of FX derivatives markets, and possibly encourage a buildup of FX debt. Future analytical work is needed to help better quantify these risks and to incorporate them into structural models.

Beyond this, there are several additional ways to extend our model and further enrich policy analysis. In future work, the model could be extended to include macroprudential policy, for example, by adding a reduced-form housing and/or banking sector. A second extension would be to consider how fiscal policy could affect the appropriate use of IPF tools. Third, it would be useful to consider a multilateral setting to assess the potential spillovers to other economies of using IPF tools. Finally, it would be useful to better understand the empirical transmission of IPF tools, and how transmission varies with structural characteristics that may differ substantially across economies. The model is currently being estimated for a group of emerging and advanced small open economies to deepen understanding of the quantitative tradeoffs that are relevant for different economies. 


\section{References}

Adjemian, S., H. Bastani, M. Juillard, F. Karame, J. Maih, F. Mihoubi, G. Perendia, J. Pfeifer, M. Ratto, and S. Villemot (2011): "Dynare: Reference Manual Version 4," Dynare Working Papers 1, CEPREMAP.

Adler, G., N. Lisack, And R. C. Mano (2019): "Unveiling the effects of foreign exchange intervention: A panel approach," Emerging Markets Review, 40, 1-1.

Adler, G. And R. Mano (2016): "The Cost of Foreign Exchange Intervention; Concepts and Measurement," IMF Working Papers 16/89, International Monetary Fund.

Adrian, T., C. Erceg, J. Lindé, P. Zabczyk, And J. Zhou (2020): “The MCM IPF Model: Reference Manual Version 1," mimeo, International Monetary Fund.

Basu, S., E. Boz, G. Gopinath, F. Roch, and F. Unsal (2020): "Integrated Monetary and Financial Policies for Small Open Economies," mimeo, International Monetary Fund.

Betts, C. And M. B. Devereux (1996): "The exchange rate in a model of pricing-to-market," European Economic Review, 40, 1007-1021.

Blanchard, O., G. Adler, and I. de Carvalho Filho (2015): "Can Foreign Exchange Intervention Stem Exchange Rate Pressures from Global Capital Flow Shocks?" NBER Working Papers 21427, National Bureau of Economic Research, Inc.

Blanchard, O., J. D. Ostry, A. R. Ghosh, and M. Chamon (2017): "Are Capital Inflows Expansionary or Contractionary? Theory, Policy Implications, and Some Evidence," IMF Economic Review, 65, 563-585.

Bruno, V. G. AND H. S. Shin (2018): "Currency depreciation and emerging market corporate distress," CEPR Discussion Papers 13298, C.E.P.R. Discussion Papers.

Calvo, G. A. (1983): "Staggered prices in a utility-maximizing framework," Journal of Monetary Economics, 12, 383-398.

Campbell, J. R., C. L. Evans, J. D. Fisher, And A. Justiniano (2012): "Macroeconomic Effects of Federal Reserve Forward Guidance," Brookings Papers on Economic Activity, 43, 1-80.

Cavallino, P. (2019): "Capital Flows and Foreign Exchange Intervention," American Economic Journal: Macroeconomics, 11, 127-170.

Chang, R. (2019): "Foreign Exchange Intervention Redux," in Monetary Policy and Financial Stability: Transmission Mechanisms and Policy Implications, ed. by A. Aguirre, M. Brunnermeier, and D. Saravia, Central Bank of Chile, vol. 26, chap. 7, 205-247. 
Christiano, L., M. Eichenbaum, and S. Rebelo (2011): "When Is the Government Spending Multiplier Large?" Journal of Political Economy, 119, 78-121.

Christiano, L. J., M. Eichenbaum, and C. L. Evans (2005): "Nominal Rigidities and the Dynamic Effects of a Shock to Monetary Policy," Journal of Political Economy, 113, 1-45.

Clarida, R., J. Gali, and M. Gertler (1999): "The Science of Monetary Policy: A New Keynesian Perspective," Journal of Economic Literature, 37, 1661-1707.

Daude, C., E. Levy Yeyati, and A. J. Nagengast (2016): "On the effectiveness of exchange rate interventions in emerging markets," Journal of International Money and Finance, 64, 239261.

Del Negro, M., S. Eusepi, M. Giannoni, A. M. Sbordone, A. Tambalotti, M. Cocci, R. B. Hasegawa, And M. H. Linder (2013): "The FRBNY DSGE model," Staff Reports 647, Federal Reserve Bank of New York.

Dixit, A. K. And J. E. Stiglitz (1977): "Monopolistic Competition and Optimum Product Diversity," The American Economic Review, 67, 297-308.

Dotsey, M. And R. G. King (2005): "Implications of state-dependent pricing for dynamic macroeconomic models," Journal of Monetary Economics, 52, 213-242.

Eggertsson, G. B. (2011): "What Fiscal Policy is Effective at Zero Interest Rates?" in NBER Macroeconomics Annual 2010, Volume 25, National Bureau of Economic Research, Inc, NBER Chapters, 59-112.

Eggertsson, G. B. And M. Woodford (2003): "The Zero Bound on Interest Rates and Optimal Monetary Policy," Brookings Papers on Economic Activity, 34, 139-235.

Erceg, C. And J. Linde (2014): "Is There A Fiscal Free Lunch In A Liquidity Trap?" Journal of the European Economic Association, 12, 73-107.

Erceg, C. J., L. Guerrieri, And C. Gust (2006): "SIGMA: A New Open Economy Model for Policy Analysis," International Journal of Central Banking, 2.

Féve, P., J. Matheron, And J.-G. Sahuc (2013): "A Pitfall with Estimated DSGE-Based Government Spending Multipliers," American Economic Journal: Macroeconomics, 5, 141-178.

Fratzscher, M., O. Gloede, L. Menkhoff, L. Sarno, and T. Stohr (2019): "When Is Foreign Exchange Intervention Effective? Evidence from 33 Countries," American Economic Journal: Macroeconomics, 11, 132-156.

Gabaix, X. (2016): “A Behavioral New Keynesian Model,” NBER Working Papers 22954, National Bureau of Economic Research, Inc. 
Galí, J. and T. Monacelli (2005): "Monetary Policy and Exchange Rate Volatility in a Small Open Economy," Review of Economic Studies, 72, 707-734.

Ghosh, A. R., J. D. Ostry, And M. Chamon (2016): "Two targets, two instruments: Monetary and exchange rate policies in emerging market economies," Journal of International Money and Finance, 60, 172-196.

Ghosh, A. R., J. D. Ostry, And M. S. Qureshi (2015): "Exchange Rate Management and Crisis Susceptibility: A Reassessment," IMF Economic Review, 63, 238-276.

(2017): "Managing the Tide; How Do Emerging Markets Respond to Capital Flows?" IMF Working Papers 17/69, International Monetary Fund.

Gopinath, G., E. Boz, C. Casas, F. J. Diez, P.-O. Gourinchas, and M. PlagborgMoller (2016): "Dominant Currency Paradigm," NBER Working Papers 22943, National Bureau of Economic Research, Inc.

Hoffmann, M., M. Krause, and P. Tillmann (2019): "International capital flows, external assets and output volatility," Journal of International Economics, 117, 242-255.

International Monetary Fund (2006): "Inflation Targeting and the IMF," IMF Policy Paper, International Monetary Fund.

- (2018): "Challenges to Steady Growth," World Economic Outlook, International Monetary Fund.

Jeanne, O. (2016): "The Macroprudential Role of International Reserves," American Economic Review, 106, 570-573.

Jeanne, O. And A. Korinek (2010): "Excessive Volatility in Capital Flows: A Pigouvian Taxation Approach," American Economic Review, 100, 403-407.

Kalemli-Ozcan, S. (2019): "U.S. Monetary Policy and International Risk Spillovers," NBER Working Papers 26297, National Bureau of Economic Research, Inc.

Kimball, M. S. (1995): "The Quantitative Analytics of the Basic Neomonetarist Model," Journal of Money, Credit and Banking, 27, 1241-1277.

Lindé, J., F. Smets, And R. Wouters (2016): "Challenges for Central Banks' Macro Models," in Handbook of Macroeconomics, ed. by J. B. Taylor and H. Uhlig, Elsevier, vol. 2 of Handbook of Macroeconomics, chap. 0, 2185-2262.

Mano, R. And S. Sgherri (2020): “One Shock, Many Policy Responses," IMF Working Papers 20/10, International Monetary Fund.

McFadden, D. (1989): "A Method of Simulated Moments for Estimation of Discrete Response Models without Numerical Integration," Econometrica, 57, 995-1026. 
Qureshi, M. S., J. D. Ostry, A. R. Ghosh, and M. Chamon (2011): "Managing Capital Inflows: The Role of Capital Controls and Prudential Policies," in Global Financial Crisis, National Bureau of Economic Research, Inc, NBER Chapters.

Schmitt-Grohe, S. And M. Uribe (2003): "Closing small open economy models," Journal of International Economics, 61, 163-185.

Svensson, L. E. (2003): "Escaping from a Liquidity Trap and Deflation: The Foolproof Way and Others," Journal of Economic Perspectives, 17, 145-166.

- (2010): "Inflation Targeting," in Handbook of Monetary Economics, ed. by B. M. Friedman and M. Woodford, Elsevier, vol. 3 of Handbook of Monetary Economics, chap. 22, 1237-1302.

TAYlor, J. B. (1993): "Discretion versus policy rules in practice," Carnegie-Rochester Conference Series on Public Policy, 39, 195-214.

Tong, H. And S.-J. Wei (2019): "Endogenous Corporate Leverage Response to a Safer Macro Environment: The Case of Foreign Exchange Reserve Accumulation," NBER Working Papers 26545, National Bureau of Economic Research, Inc.

TURnovsky, S. J. (1985): "Domestic and foreign disturbances in an optimizing model of exchangerate determination," Journal of International Money and Finance, 4, 151-171.

Vegh, C. A. And G. Vuletin (2013): "Overcoming the Fear of Free Falling: Monetary Policy Graduation in Emerging Markets," in The Role of Central Banks in Financial Stability How Has It Changed?, ed. by D. D. Evanoff, C. Holthausen, G. G. Kaufman, and M. Kremer, World Scientific Publishing Co. Pte. Ltd., World Scientific Book Chapters, chap. 6, 105-129.

Yun, T., J. D. Lopez-SAlido, And A. Levin (2007): "Strategic Complementarities and Optimal Monetary Policy," 2007 Meeting Papers 1016, Society for Economic Dynamics. 


\section{Technical Appendix}

\section{A The Model Environment}

This Appendix provides more details on the full non-linear model at the heart of our analysis. We focus on the key optimization problems and the resulting optimality and market clearing conditions. Step by step derivations of all these equations and their linearization - yielding the conditions discussed in Section 2 and used in the simulations - can be found in a companion document Adrian et al. (2020).

\section{A.1 Households and Wage Setting}

The utility functional for a member of household $h$ is,

$\mathbb{E}_{t} \sum_{j=0}^{\infty} \beta^{j} \varsigma_{t+j}\left\{\frac{\left(\tilde{C}_{t+j}(h)-\varkappa \tilde{C}_{t+j-1}-\tilde{C} \nu_{t+j}\right)^{1-\frac{1}{\sigma}}}{1-\frac{1}{\sigma}}-\chi_{0} \frac{N_{t+j}^{1+\chi}(h)}{1+\chi}+\mu_{0} F\left(\frac{\mathcal{M}_{t+j+1}(h)}{P_{C, t+j}}\right)\right\}$.

We assume that both private and public consumption yield utility, that is ${ }^{17}$

$$
\tilde{C}_{t}(h)=C_{t}(h)+\eta_{0} G_{t}
$$

with $C_{t}(h)$ and $N_{t}(h)$ denoting the household's current consumption and hours of labor, respectively, $\varkappa \in(0,1)$ measuring the importance of external consumption habits, and $\nu_{t+j}$ representing a demand shock. ${ }^{18}$ The shock to the discount factor $\varsigma_{t}$ has been widely used in the zero lower bound (ZLB) literature (see e.g., Eggertsson, 2011; Christiano et al., 2011) as a driving force of the "Great Recession". Following Eggertsson and Woodford (2003), the sub-utility function over real balances, $F(\cdot)$, is assumed to have a satiation point for $\overline{\mathcal{M}} / P$. Hence, inclusion of money - which is a zero

${ }^{17}$ As explained in Féve et al. (2013), $\eta_{0}$ measures the degree of complementarity between private $(C)$ and public $(G)$ consumption. When $\eta_{0}$ is nil we recover the standard specification in which public consumption does not yield any utility directly.

${ }^{18} \mathrm{As}$ is standard, we assume that household $h$ derives utility from consuming quantity $C_{D, t}$ of a domestically produced basket of goods and quantity $M_{C, t}$ of imported varieties, with total consumption given by

$$
C_{t}=\left(\left(1-\omega_{C}\right)^{\frac{\rho_{C}}{1+\rho_{C}}} C_{D, t}^{\frac{1}{1+\rho_{C}}}+\omega_{C}^{\frac{\rho_{C}}{1+\rho_{C}}} M_{C, t}^{\frac{1}{1+\rho_{C}}}\right)^{1+\rho_{C}}
$$

This assumption implies that demand schedules for domestically-produced and imported goods equal,

$$
C_{D, t}=\left(1-\omega_{C}\right)\left(\frac{P_{D, t}}{P_{C, t}}\right)^{-\frac{\left(1+\rho_{C}\right)}{\rho_{C}}} C_{t} \quad \text { and } \quad M_{C, t}=\omega_{C}\left(\frac{P_{M, t}}{P_{C, t}}\right)^{-\frac{\left(1+\rho_{C}\right)}{\rho_{C}}} C_{t},
$$

where $P_{D, t}$ and $P_{M, t}$ denote the respective prices of the domestic and imported bundles, with expenditure minimization further implying,

$$
P_{C, t} \equiv\left(\left(1-\omega_{C}\right) P_{D, t}^{-\frac{1}{\rho_{C}}}+\omega_{C} P_{M, t}^{-\frac{1}{\rho_{C}}}\right)^{-\rho_{C}}
$$


nominal interest asset - provides a rationale for the zero lower bound on nominal interest rates. ${ }^{19}$ Finally, we require $0<\beta<1$, and $\sigma, \chi, \chi_{0}, \mu_{0}>0$.

Household $h$ faces a flow budget constraint in period $t$ which equates the combined expenditure on goods and on the net accumulation of financial assets to its disposable income,

$$
\begin{aligned}
& P_{C, t} C_{t}(h)+\left(\mathcal{M}_{t+1}(h)-\mathcal{M}_{t}(h)\right)+\int_{s \in \Omega} \xi_{t, t+1}(s) B_{D, t+1}(h)(s) d s+B_{G, t}(h)+\varepsilon_{t} B_{t}^{i n t} \\
= & W_{t} N_{t}(h)+R_{K, t} K+\Xi_{t}(h)-T_{t}+B_{D, t}(h)+I_{t-1} B_{G, t-1}(h)+\varepsilon_{t} I_{t-1}^{*} \Phi\left(\frac{B_{t-1}^{i n t}}{P_{D, t} Y}, \phi_{t-1}\right) B_{t-1}^{i n t} .
\end{aligned}
$$

Household $h$ earns per capita labor income $W_{t} N_{t}(h)$ with each member additionally possessing a fixed stock of capital $(K)$ which is leased to firms at the rental rate $R_{K, t} \cdot{ }^{20 / 21}$ Households also receive an aliquot share $\Xi_{t}(h)$ of the profits of all firms along with lump sum taxes or transfers from the government, $T_{t}$. Households maximize the utility functional (37) with respect to their consumption, hours worked, purchases of bonds, and holdings of contingent claims. The optimization is subject to the budget constraint (39), and takes asset prices, the rental price of capital, and the price of the consumption bundle as given.

Financial asset accumulation of a typical member of household $h$ consists of increases in nominal money holdings $\left(\mathcal{M}_{t+1}(h)-\mathcal{M}_{t}(h)\right)$ and the net acquisition of bonds. We assume that agents within a country can engage in frictionless trading of a complete set of contingent claims, while, as alluded to above, trade in international assets is restricted to a single non-state-contingent nominal

${ }^{19}$ We maintain the assumption that money is additive and that $\mu_{0}$ is small, so that changes in real money balances have negligible implications for government debt and output.

${ }^{20}$ We assume that each household is a monopolistic supplier of differentiated labor service to the intermediate goodsproducing sector. In line with Erceg et al. (2006) we also posit a representative labor aggregator combining household's labor hours in the same proportions as firms would choose. Accordingly, the domestic aggregate labor index $L_{t}$ has the Dixit-Stiglitz form

$$
L_{t}=\left[\int_{0}^{1}\left(N_{t}(h)\right)^{\frac{1}{1+\theta} w} d h\right]^{1+\theta_{w}}
$$

where $\theta_{w}>0$ and $N_{t}(h)$ is hours worked by a typical member of household $h$.

The aggregator minimizes the cost of producing a given amount of the aggregate labor index, taking each household's wage rate $W_{t}(h)$ as given, and then sells units of the labor index to the production sector at their cost $W_{t}$, which is given by

$$
W_{t}=\left[\int_{0}^{1}\left(W_{t}(h)\right)^{\frac{-1}{\theta w}} d h\right]^{-\theta_{w}}
$$

with demand for the labor services of a typical member of household $h$ given by

$$
N_{t}(h)=\left[\frac{W_{t}(h)}{W_{t}}\right]^{-\frac{1+\theta_{w}}{\theta} w} L_{t} .
$$

${ }^{21}$ In addition, forward looking households are assumed to set nominal wages in staggered contracts: with probability $1-\xi_{w}$, each member of a household is allowed to reoptimize her wage contract, with the resulting optimality condition equating the present discounted value of working an additional unit of time to the discounted marginal cost. Households not allowed to optimize reset wages according to

$$
W_{t}(h)=\Pi_{w} W_{t-1}(h)
$$

where $\Pi_{w}$ denotes steady state wage inflation. 
bond. The term $\xi_{t, t+1}(s)$ denotes the time $t$ price of an asset that will pay one unit of domestic currency in a particular state of nature $s$ at date $t+1$, with $B_{D, t+1}(h)(s)$ representing the quantity of such claims purchased, which implies that net purchases of state-contingent domestic bonds are given by $\int_{s \in \Omega} \xi_{t, t+1}(s) B_{D, t+1}(h)(s) d s-B_{D, t}(h)$. In addition, $B_{G, t}(h)-I_{t-1} B_{G, t-1}(h)$ denotes net expenditure on domestic government bonds, where $B_{G, t}(h)$ denotes nominal expenditure on these bonds in period $t$ and $I_{t}$ is the corresponding nominal yield paid in period $t+1$ but assumed to be known ex ante. Finally, $B_{t}^{\text {int }}$ is the position taken in the foreign currency denominated internationally traded nominal bond. The bond promises to pay a rate of $I_{t}^{*}$ next period along with a premium $\Phi(\cdot, \cdot)$, with net purchases of the internationally traded bonds given by $\varepsilon_{t} B_{t}^{\text {int }}-$ $\varepsilon_{t} \Phi\left(b_{t-1}^{i n t}, \phi_{t-1}\right) I_{t-1}^{*} B_{t-1}^{i n t}$, where

$$
b_{t}^{i n t} \equiv \frac{B_{t}^{i n t}}{P_{D, t} Y}
$$

denotes the real aggregate net foreign asset position relative to domestic trend output and $\varepsilon_{t}$ denotes the nominal exchange rate.

Following Turnovsky (1985), the premium $\Phi(\cdot, \cdot)$ captures the costs for domestic households of undertaking positions in the international financial market, and is specified as

$$
\Phi\left(b_{t}^{i n t}, \phi_{t}\right) \equiv e^{-\phi^{i n t}\left(b_{t}^{i n t}-b^{i n t}\right)+\phi_{t}}
$$

where $\phi^{\text {int }}>0$, implying that $\partial \Phi / \partial b_{t}^{\text {int }}<0$ and $\Phi(0,0)=1$, and where the risk-premium shock $\phi_{t}$ is assumed to follow a stationary $\mathrm{AR}(1)$ process: $^{22}$

$$
\phi_{t}=\rho_{\phi} \phi_{t-1}+\varepsilon_{\phi, t}, \varepsilon_{\phi, t} \sim \text { i.i.d.N }\left(0, \sigma_{\varepsilon}^{2}\right)
$$

Maximizing the utility functional (37) subject to (39) w.r.t. $B_{t}^{\text {int }}(h)$ results in the following first-order condition

$$
1=\beta \mathbb{E}_{t} \frac{\varsigma_{t+1}}{\varsigma_{t}} \frac{\Lambda_{t+1}}{\Lambda_{t}} \frac{I_{t}^{*} \Phi\left(b_{t}^{i n t}, \phi_{t}\right)}{\Pi_{C, t+1}} \frac{\varepsilon_{t+1}}{\varepsilon_{t}}
$$

with the optimality condition w.r.t. $B_{G, t}(h)$ stating that

$$
1=\beta \mathbb{E}_{t} \frac{\varsigma_{t+1}}{\varsigma_{t}} \frac{\Lambda_{t+1}}{\Lambda_{t}} \frac{I_{t}}{\Pi_{C, t+1}} .
$$

Equating the right hand sides we obtain

$$
I_{t} \mathbb{E}_{t} \frac{\varsigma_{t+1} \Lambda_{t+1}}{\Pi_{C, t+1}}=\frac{I_{t}^{*} \Phi\left(b_{t}^{i n t}, \phi_{t}\right)}{\varepsilon_{t}} \mathbb{E}_{t} \frac{\varsigma_{t+1} \Lambda_{t+1} \varepsilon_{t+1}}{\Pi_{C, t+1}}
$$

\footnotetext{
${ }^{22}$ Thus, if the domestic economy as a whole is a net borrower $\left(b_{t}^{\text {int }}<0\right)$ domestic households are charged a premium on the foreign interest rate, while if the domestic economy is a net lender $\left(b_{t}^{\text {int }}>0\right)$ households receive a lower remuneration on their international savings.
} 
which can be log-linearized and further simplified to arrive at

$$
i_{t}-i_{t}^{*}=-\phi^{i n t}\left(b_{t}^{i n t}-b^{i n t}\right)+\phi_{t}+\mathbb{E}_{t} \varepsilon_{t+1}-\varepsilon_{t}
$$

which is the risk-adjusted UIP condition. ${ }^{23}$ This equation states that the wedge between the domestic and foreign interest rate is determined by an endogenous component (the net foreign asset position) and an exogenous component (the spread shock).

With incomplete financial markets the dynamics of net foreign assets is given by

$$
B_{t}^{i n t}=T B_{t}+I_{t-1}^{*} \Phi\left(b_{t-1}^{i n t}, \phi_{t-1}\right) B_{t-1}^{i n t}
$$

and so using the definition of the trade balance and dividing through by $P_{D, t} Y$, we can obtain

$$
\frac{B_{t}^{i n t}}{P_{D, t} Y}=\frac{\zeta^{*}}{\zeta} \frac{1}{Y}\left[M_{C, t}^{*}+M_{G, t}^{*}\right]-\frac{P_{M, t}}{P_{D, t} Y}\left[M_{C, t}+M_{G, t}\right]+\frac{I_{t-1}^{*}}{\Pi_{D, t}} \Phi\left(b_{t-1}^{i n t}, \phi_{t-1}\right) \frac{B_{t-1}^{i n t}}{P_{D, t} Y} .
$$

Differentiating this equation, using expressions for trade shares and imposing the assumptions that $Y=Y^{*}, C=C^{*}, \rho_{C}=\rho_{C}^{*}$ and $\rho_{G}=\rho_{G}^{*}$, this expression simplifies to ${ }^{24}$

$$
\begin{aligned}
b_{t}^{i n t}= & {\left[\omega_{C} s_{c y}\left(\frac{\left(1+\rho_{C}\right)}{\rho_{C}}\left(2-\omega_{C}^{*}-\omega_{C}\right)-1\right)+\omega_{G} s_{g y}\left(\frac{\left(1+\rho_{G}\right)}{\rho_{G}}\left(2-\omega_{G}^{*}-\omega_{G}\right)-1\right)\right] \gamma_{M D, t} } \\
& -\omega_{C} s_{c y}\left(c_{t}-c_{t}^{*}\right)-\omega_{G} s_{g y}\left(g_{t}-g_{t}^{*}\right)+\left(1+r^{*}\right) b_{t-1}^{\text {int }}
\end{aligned}
$$

where $1+r^{*} \equiv\left(1+i^{*}\right) /(1+\pi)$.

\section{A.2 Firms and Price-Setting}

\section{A.2.1 Final Goods Production}

Because households have identical preferences, it is convenient to assume that a representative aggregator combines the differentiated intermediate products $Y_{t}(f)$ into a composite home-produced good $Y_{D, t}$. The technology for transforming these intermediate goods into the final output good is specified as in Kimball (1995) and subsequently used e.g. in Dotsey and King (2005) and Yun et al. (2007). ${ }^{25}$ More specifically, the aggregator chooses the bundle of goods that minimizes the cost of producing $Y_{D, t}$, taking as given the price $P_{D, t}(f)$ of each intermediate variety $Y_{D, t}(f)$. We show in Adrian et al. (2020) that the final output good price $P_{D, t}$ is given by

$$
P_{D, t}=\frac{1}{(1+\psi)}\left(\int_{0}^{1} P_{D, t}^{-\frac{1+\psi+\psi \theta_{p}}{\theta_{p}}}(f) d f\right)^{-\frac{\theta_{p}}{1+\psi+\psi \theta_{p}}}+\frac{\psi}{(1+\psi)} \int_{0}^{1} P_{D, t}(f) d f
$$

\footnotetext{
${ }^{23}$ After adjusting for discounting this becomes equation 9, featured in Section 2.1.

${ }^{24}$ All the intermediate steps are discussed in Adrian et al. (2020) and are omitted here to cut on space.

${ }^{25}$ Importantly, the specification nests the popular Dixit and Stiglitz (1977) case when $\psi=0$.
} 
i.e. the domestic producer price index will be a weighted average of a Dixit and Stiglitz (1977) price index and a linear one. Furthermore, we show that demand for individual variety $f$ equals ${ }^{26}$

$$
Y_{D, t}(f)=\left\{\frac{1}{(1+\psi)}\left(\frac{P_{D, t}(f)}{\left(\int_{0}^{1} P_{D, t}^{-\frac{1+\psi+\psi \theta_{p}}{\theta_{p}}}(f) d f\right)^{-\frac{\theta_{p}}{1+\psi+\psi \theta_{p}}}}\right)^{-\frac{\left(1+\theta_{p}\right)(1+\psi)}{\theta_{p}}}+\psi\right\} Y_{D, t} .
$$

We also assume a representative aggregator in the foreign economy who combines the differentiated home products $X_{t}(f)$ into a single index for foreign imports $M_{t}^{*}$ which are sold at price $P_{M, t}^{*}$.

\section{A.2.2 Production of Domestic Intermediate Goods}

There is a continuum of differentiated intermediate goods (indexed by $i \in[0,1]$ ) in the home country, each of which is produced by a single monopolistically competitive firm. As in Betts and Devereux (1996) intermediate firms charge different prices at home and abroad with demand for their products varying inversely with the output price and proportional to aggregate demand in the respective market.

Each producer utilizes capital services $K_{t}(i)$ and a labor index $L_{t}(i)$ to produce its respective output good subject to a Cobb-Douglas production function:

$$
Y_{D, t}(i)=K_{t}(i)^{\alpha}\left(Z_{t} L_{t}(i)\right)^{1-\alpha}
$$

where $Z_{t}$ denotes a stationary, country-specific shock to the level of technology. Intermediate goods' producers face perfectly competitive factor markets for hiring capital and labor. Thus, each firm chooses $K_{t}(i)$ and $L_{t}(i)$, taking as given both the rental price of capital $R_{K, t}$ and the aggregate wage rate $W_{t}$. Accordingly, standard static first-order conditions for cost minimization imply that all intermediate firms have identical marginal cost per unit of output equal to,

$$
M C_{t}=\left(\frac{W_{t}}{1-\alpha}\right)^{1-\alpha}\left(\frac{R_{K, t}}{\alpha}\right)^{\alpha} \frac{1}{Z_{t}^{1-\alpha}}
$$

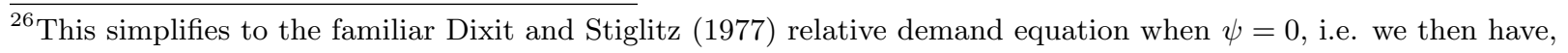

$$
Y_{D, t}(f)=\left(\frac{P_{D, t}(f)}{P_{D, t}}\right)^{-\frac{\left(1+\theta_{p}\right)}{\theta_{p}}} Y_{D, t} .
$$

In addition, the fact that

$$
P_{D, t} Y_{D, t}=\int_{0}^{1} Y_{D, t}(f) P_{D, t}(f) d f
$$

clarifies why $P_{D, t}$, defined in Equation 44 above, can be interpreted as the "price" of the aggregate production bundle. 
with the rate of return on capital $R_{K, t}$ linked to wages $W_{t}$ via,

$$
R_{K, t}=\frac{\alpha}{1-\alpha} W_{t} \frac{L_{t}}{K}
$$

\section{A.2.3 Optimal Price Setting}

Intermediate goods' producing firms set home and foreign prices in Calvo-style staggered contracts. We assume, in particular, that firm $i$ faces a constant probability $1-\xi_{p}$ of being able to reoptimize the price it charges domestically and $1-\xi_{p, x}$ of being able to reoptimize its price abroad. Following Calvo (1983), we assume that reoptimizing firms set their domestic price $P_{D, t}^{\diamond}(i)$ to maximize expected profits

$$
\max _{P_{D, t}^{\diamond}(i)} \sum_{j=0}^{\infty} \xi_{p}^{j} \mathbb{E}_{t} \beta^{j} \frac{\varsigma_{t+j}}{\varsigma_{t}} \frac{\Lambda_{t+j}}{\Lambda_{t}} \frac{P_{C, t}}{P_{C, t+j}}\left[\Pi_{D}^{j} P_{D, t}^{\diamond}(i) Y_{D, t+j \mid t}(i)-T C_{t+j \mid t}(i)\right]
$$

subject to sequences of demand curves specified in Equation 45, with corresponding expressions for the foreign price optimization problem (which we skip for parsimony). As is standard, the firm discounts profits received at date $t+j$ using the household's stochastic discount factor, to account for the fact that all firms are ultimately owned by households and aim to maximize their owner's welfare.

In contrast, firms which are not allowed to reoptimize their prices in period $t$ (a fraction $\xi_{p}$ ), mechanically index their prices $P_{D, t}^{i n d}(i)$ according to

$$
P_{D, t}^{i n d}(i)=\Pi_{D} P_{D, t-1}(i)
$$

where $\Pi_{D}$ is the steady-state (gross) PPI inflation rate. This form of lagged indexation is a mechanism for introducing inflation inertia into the key price-setting equations.

\section{A.3 Monetary and Fiscal Policy}

Our benchmark model specification comprises a simple Taylor-type instrument rule (Taylor, 1993) specified as

$$
I_{t}=I+\psi_{\pi}\left[\Pi_{C, t}-\Pi_{C}\right]+\psi_{x}\left(Y_{D, t} / Y_{D, t}^{p o t}-1\right),
$$

where $I$ denotes the steady-state gross nominal interest rate and $\Pi_{C}$ is the steady state consumer price inflation. As is standard, we assume that the central bank is concerned with deviations of consumer price inflation from target as well as deviations of output from its potential level.

The evolution of nominal government debt, $B_{G, t}$, is determined by the following flow budget constraint

$$
B_{G, t}=I_{t-1} B_{G, t-1}+P_{t} G_{t}-T_{t}
$$

where $P_{t} G_{t}$ denotes nominal government expenditures, and where changes in the government's net asset position $\left(B_{G, t}-I_{t-1} B_{G, t-1}\right)$ and spending are financed using non-distortionary lump-sum 
taxes $T_{t}$ such that the budget is balanced each period. Public consumption, $G_{t}$, is for simplicity assumed to comprise only the domestically produced final good, and follows a simple AR(1) process,

$$
G_{t}=\left(1-\rho_{G}\right) G+\rho_{G} G_{t-1}+\varepsilon_{G, t}
$$

\section{A.4 Importing and Exporting Firms}

The import sector consists of firms that buy a homogenous good in the world market and transform it into a differentiated consumption good $M_{C, t}(i)$ (through access to a "differentiating" technology, i.e. brand naming). There is a continuum of such firms selling their differentiated consumption goods to the households.

The importing firms buy the homogenous good at price $P_{t}^{*}$ in the international market. In order to allow for incomplete exchange rate pass-through to consumption import prices we assume local currency price stickiness. In particular, the importing firms follow Calvo price setting and are allowed to change their price only when they receive a random price change signal, which occurs with probability $\left(1-\xi_{m, c}\right)$. We denote the reoptimized price for an imported consumption good as $P_{M, t}^{\diamond}$ (ignoring the $i$ index, as all reoptimizing firms will set identical prices). As in the other sectors, with probability $\xi_{m, c}$ the firm does not reoptimize and its price is then indexed to steady state inflation. The importing firms thus face the following optimization problem:

$$
\max _{P_{M, t}^{\diamond}} \sum_{j=0}^{\infty}\left(\beta \xi_{m, c}\right)^{j} \mathbb{E}_{t} \frac{\varsigma_{t+j}}{\varsigma_{t}} \frac{\Lambda_{t+j}}{\Lambda_{t}} \frac{P_{C, t}}{P_{C, t+j}}\left[\Pi_{D}^{j} P_{M, t}^{\diamond} M_{C, t+j \mid t}(i)-T C_{t+j \mid t}^{m}(i)\right]
$$

where the total costs expression $T C_{t+j \mid t}^{m}(i)$ includes fixed real costs ensuring that import profits are zero in steady state.

The final import consumption good is a composite of a continuum of $i$ differentiated imported goods, each supplied by a different firm, with import aggregation according to:

$$
M_{C, t}=\left[\int_{0}^{1}\left(M_{C, t}(i)\right)^{\frac{1}{\lambda_{t}^{m}}} d i\right]^{\lambda_{t}^{m}}, \quad 1 \leq \lambda_{t}^{m}<\infty .
$$

As discussed in Adrian et al. (2020) it can then be shown that each importing firm $i$ faces the demand for imported consumption goods given by

$$
M_{C, t}(i)=\left(\frac{P_{M, t}(i)}{P_{M, t}}\right)^{-\frac{\lambda_{t}^{m}}{\lambda_{t}^{m}-1}} M_{C, t}
$$

and the log-linearized pricing equations resulting from price optimization can be written as familiar Phillips curve relationships for the price of imported goods. Finally, the process for the time varying markups on the import consumption and investment goods are assumed to follow

$$
\lambda_{t}^{m}=\left(1-\rho_{\lambda^{m}}\right) \lambda^{m}+\rho_{\lambda^{m}} \lambda_{t-1}^{m}+\varepsilon_{\lambda^{m}, t}
$$


On the export side, firms buy the final domestic good and differentiate it by brand naming. Subsequently they sell the continuum of differentiated goods to the households in the foreign market. The marginal cost is therefore equal to the price of the domestic good $P_{t}$. Each exporting firm $i$ faces the following demand $X_{t}(i)$ for its product

$$
X_{t}(i)=\left(\frac{P_{X, t}(i)}{P_{X, t}}\right)^{-\frac{\lambda_{x, t}}{\lambda_{x, t}-1}} X_{t}
$$

where we assume that the export price $P_{X, t}(i)$ is invoiced in the local currency of the export market. The exogenous process $\lambda_{x, t}$ determines the markup and takes the form of a first-order auto-regression

$$
\lambda_{t}^{x}=\left(1-\rho_{\lambda^{x}}\right) \lambda^{x}+\rho_{\lambda^{x}} \lambda_{t-1}^{x}+\varepsilon_{\lambda^{x}, t} .
$$

In order to allow for incomplete exchange rate pass-through in the export market, we assume that export prices are sticky in the foreign currency. To model this we again rely on the Calvo setup. Broadly, when setting their prices, export firms factor in their own price relative to the aggregate export price, but they also care about the price of the domestic good, since this determines the export firms' marginal cost. In line with the treatment in several over sectors firms not allowed to reoptimize are assumed to index to steady state inflation, with

$$
P_{X, t}(i)=\Pi_{D} P_{X, t-1}(i)
$$

As in the import sector, the log-linearized optimality conditions can be expressed in terms of a standard Phillips curve relationship linking export prices to the evolution of marginal cost.

\section{A.5 Market Clearing}

There are two types of market clearing conditions. The first equates the demand and supply of domestically produced intermediate goods, and can be stated as

$$
Y_{D, t}=\left(P_{D, t}^{\#}\right)^{-1} K^{\alpha}\left(Z_{t} L_{t}\right)^{1-\alpha}
$$

where price dispersion $P_{D, t}^{\#}$ satisfies,

$$
P_{D, t}^{\#} \equiv \frac{\vartheta_{t}^{\frac{1+\theta_{p}}{\theta_{p}}(1+\psi)}}{(1+\psi)} \int_{0}^{1}\left(\frac{P_{D, t}(f)}{P_{D, t}}\right)^{-\frac{1+\theta_{p}}{\theta_{p}}(1+\psi)} d f+\frac{\psi}{(1+\psi)}
$$

The second market clearing condition notes that, at the level of the individual firm $f$ it has to be that

$$
\forall f \in[0,1]: Y_{t}(f)=Y_{D, t}(f)+X_{t}(f)
$$

and so, more broadly, the quantity of goods produced domestically has to equal the sum of domestic 
and foreign, public and private demands,

$$
\zeta Y_{D, t}=\zeta C_{D, t}+\zeta G_{D, t}+\zeta^{*} M_{C, t}^{*}+\zeta^{*} M_{G, t}^{*} \Longleftrightarrow Y_{D, t}=C_{D, t}+G_{D, t}+\frac{\zeta^{*}}{\zeta}\left[M_{C, t}^{*}+M_{G, t}^{*}\right]
$$

where we have adjusted by the size of the home and foreign economies to move from per-capita concepts to economy-wide aggregates. 